University of Rhode Island

DigitalCommons@URI

Open Access Dissertations

2007

\title{
Enhancing Hardiness in Urban Adolescent Males: A Hardiness Curriculum
}

Lea Beth Lockwood

University of Rhode Island

Follow this and additional works at: https://digitalcommons.uri.edu/oa_diss

\section{Recommended Citation}

Lockwood, Lea Beth, "Enhancing Hardiness in Urban Adolescent Males: A Hardiness Curriculum" (2007). Open Access Dissertations. Paper 1000.

https://digitalcommons.uri.edu/oa_diss/1000

This Dissertation is brought to you for free and open access by DigitalCommons@URI. It has been accepted for inclusion in Open Access Dissertations by an authorized administrator of DigitalCommons@URI. For more information, please contact digitalcommons-group@uri.edu. 
ENHANCING HARDINESS IN URBAN ADOLESCENT MALES: A HARDINESS

\section{CURRICULUM}

BY

LEA BETH LOCKWOOD

A DISSERTATION SUBMITTED IN PARTIAL FULFILLMENT OF THE REQUIREMENTS FOR THE DEGREE OF

DOCTOR OF PHILOSOPHY

$\mathbb{N}$

PSYCHOLOGY

UNIVERSITY OF RHODE ISLAND

2007 


\begin{abstract}
This exploratory study examined the impact of a school-based psycho-educational group intervention for $9^{\text {th }}$ grade urban adolescent males. The group intervention was created to enhance measured levels of hardiness attitudes, self-esteem, and perceived social support in a sample $(N=51)$ of high-risk adolescent males attending an alternative high school in Providence, RI. Approximately half of the sample $(n=22)$ attended the eight-week intervention. Participants were given the Personal Views Survey - Third Edition, the Rosenberg Self-esteem Scale, and the Child and Adolescent Social Support Scale as both pre- and posttests. Although no impact on the treatment outcomes was found, additional research is deemed warranted. Results of this study provide some insight into an initial attempt to increase hardiness, self-esteem, and perceived social support through an intervention. The suggestions offered hope to educate others in the future on how to design a hardiness curriculum.
\end{abstract}




\section{ACKNOWLEDGEMENTS}

This project truly was a team effort. From the many weekends that my family spent helping me figure out a "balance" of family, work and writing, to my friends who just listened over coffee, to my work colleagues who supported me, I am blessed to have had the opportunity to witness love in action.

I would like to thank my dissertation committee, Drs. Dan Koonce, Anne Seitsinger and Jerry Cohen. In particular, thank you Dr. Cohen for becoming my "surrogate" major professor. You went above and beyond what was initially asked of you and I am grateful. I am thankful for the guidance and support of Maryellen Butke, Vera Toro and Diana Kurlander. I have learned so much from you three. It has been an absolute joy working on this project together. I am also indebted to the students at the Met School. Your openness allowed us to try something new and I appreciate all of your effort in this endeavor.

Thank you Maureen McDermott and Robert Olschefskie, two of the best parents in the world. I am also grateful for the unwavering support from Kathleen and Willem van Rijn. Revising the paper at the local gym in Cape Cod on Patriot's Day showed me how dedicated you two are and it means the world to me. Many thanks also to Grace Baggot and Tom Frank, who have both contributed so much to our lives throughout the last year.

To my daughter, Zoe, who came into this world months before my proposal: you are my sunshine! Finally, to David. You believed in me every minute of every day since we met. Your encouragement in all of our nightly "talks" is what has gotten me through this. Thank you for this and so much more. 
Table of Contents

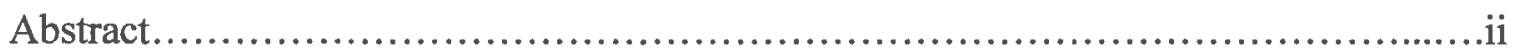

Acknowledgements....................................................................

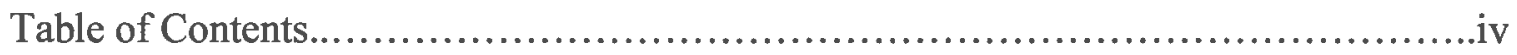

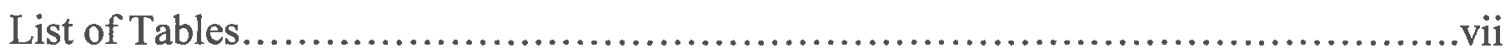

List of Figures.......................................................................

Chapter 1 ..............................................................................

- Introduction..............................................................................

- Statement of the Problem.........................................................

- Statement of Purpose and Research Question...................................6

- Definition of Terms...........................................................

- Organization of the Study ................................................

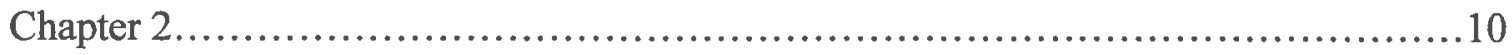

- Review of Literature .................................................... 10

○ Resilience............................................................ 10

○ Hardiness Construct...................................................13

○ Resilient Males: Self-esteem and Social Support......................17

○ Adolescent Development...........................................20

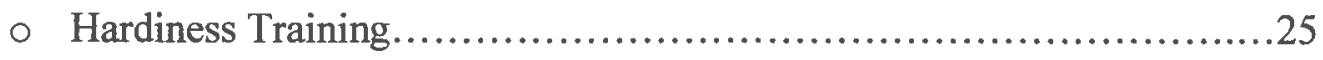

○ Rationale for a Group Intervention...................................27

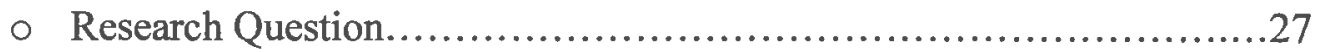

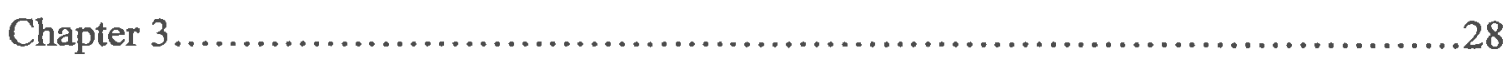

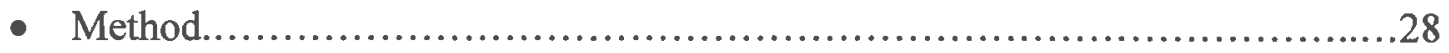


○ Sample Size and Recruitment........................................28

○ Participants.........................................................28

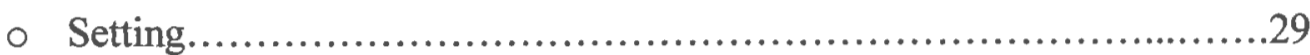

○ Instruments...............................................................

- Personal Views Survey, $3^{\text {rd }}$ Edition, Revised (PVS-IIIR) ................32

○ Rosenberg Self-esteem Scale..............................................33

- The Child and Adolescent Social Support Scale ..........................34

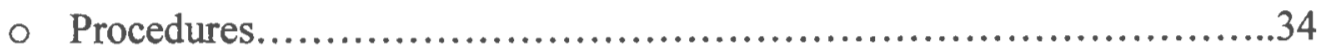

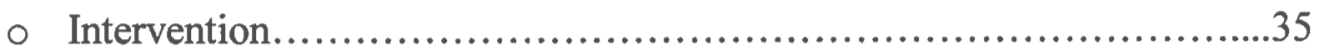

○ Research Design..................................................44

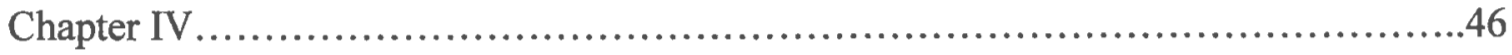

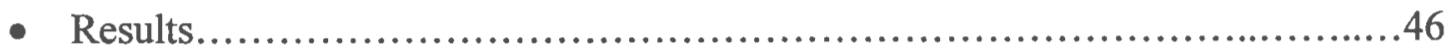

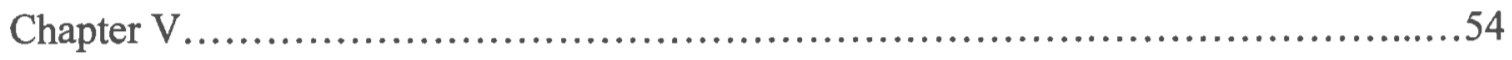

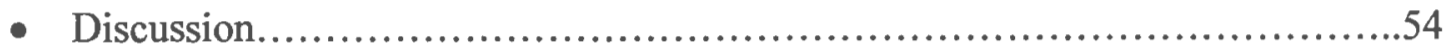

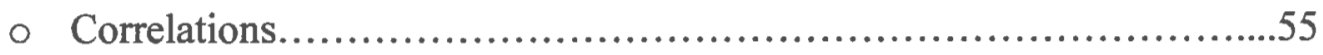

○ Hardiness Attitudes................................................56

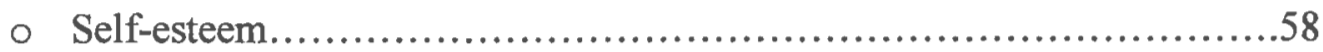

○ Perceived Total Social Support...........................................59

○ Limitations of the Research..........................................60

○ Implications for Research.........................................62

○ Directions for Future Research.......................................62

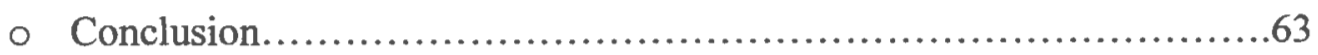

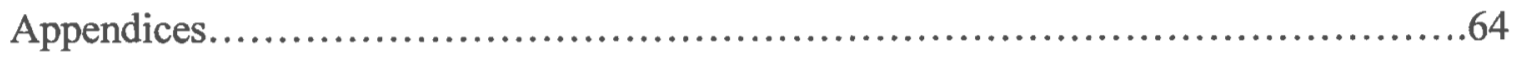


- Appendix A: IRB Approval Sheet......................................64

- Appendix B: Hardiness Group Manual....................................65

- Appendix C: Personal Views Survey-III Revised.............................86

- Appendix D: Rosenberg Self Esteem Scale ...............................88

- Appendix E: The Child and Adolescent Social Support Scale ....................89

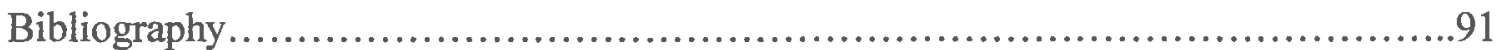


List of Tables

Table 1 Tests of Normality: Hardiness attitudes, Self-esteem, Total Social Support......46

Table 2 Intercorrelations Between Dependent Variables for Students (Pretest).........47

Table 3 Intercorrelations Between Dependent Variables for Control Group (Posttest)...48

Table 4 Intercorrelations Between Dependent Variables for Experimental Group

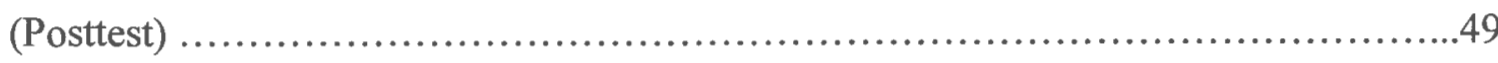

Table 5 Pre- and Posttest Means........................................................49

Table 6 Analysis of Variance for Hardiness Attitudes................................................50

Table 7 Analysis of Variance for Self Esteem....................................................51

Table 8 Analysis of Variance for Total Social Support..............................................52

Table 9 Lessons Learned from the Group...........................................53 
List of Figures

Figure 1 The Hardiness Model...................................................15 


\section{CHAPTER I}

\section{INTRODUCTION}

Resilience is a relatively well-known multidimensional construct that was first conceptualized almost 30 years ago (Werner \& Smith, 1977). It has been defined as the positive adaptation of individuals when they are faced with significant adversity (Luthar, Cicchetti, \& Becker, 2000; Masten \& Coatsworth, 1998). In the developmental literature, resilience has been shown to be a protective psychological factor that is common among children growing up in highly adverse conditions (Garmezy, 1991; Luthar et al., 2000; Masten, 2001; Rutter, 1999; Werner, 1995). Accordingly, the identification of the characteristics of resilient adolescents seems important for facilitating the development of competence in the domains needed for youth to perform well in the future.

The characteristics of resilient youth have been classified into three broad categories: individual, familial and extrafamilial (Masten \& Coatsworth, 1998). The most common individual characteristics of resilient youth include good intellectual functioning and self-esteem (Masten \& Coatsworth, 1998). Common familial characteristics of resilient youth include close relationships to caring parents, warmth and extended family support (Masten \& Coatsworth, 1998). The most frequently cited extra-familial level qualities include supportive relationship with adults other than the youth's parents (Luthar \& Zigler, 1991; Werner, 1990), a positive school climate (Blum, McNeely, \& Rinehart, 2002; Bogenschneider, Wu, Rafaelli, \& Tsay, 1998; Brand, Felner, Shim, Seitsinger, \& Dumas, 2003; Rutter, 1987), and peer group characteristics (Blum et al., 
2000; Mahoney \& Stattin, 2000; Perry, 2000). Moreover, resilient individuals are believed to have some combination of internal (e.g., personality characteristic) and external (e.g., social support) resources from which they can draw when faced with adversity (Masten, 2001).

Over the past 25 years, extensive evidence suggests that the personality trait of hardiness has been identified as one of multiple pathways to resilience (Bonanno, 2004; Kobasa, Maddi, \& Kahn, 1982; Maddi, 2005) that may help to buffer stress in adolescents and adults. Hardiness emerged from existential personality theory and was defined by Kobasa et al. (1982) as "a constellation of personality characteristics that function as a resistance resource in the encounter with stressful life events" (p. 169). In other words, these personality characteristics (e.g., commitment, control, and challenge) act to protect (or enhance) one's performance under stress. For example, recent studies have shown that hardiness attitudes promote resiliency in a variety of ways such as when military recruits undergo intensive basic combat training (Bartone, 1999), when nurses confront death and dying in hospice settings (Keane, Ducette, \& Adler, 1985), or when high school graduates transition to a college setting (Maddi et al., 2002). These illustrations provide strong evidence that hardiness attitudes can promote resiliency in response to the common demands and pressures of daily life (Maddi, 2002). As described by Kobasa (1979b), this personality variable consists of three interrelated qualities: commitment (rather than alienation), control (rather than powerlessness), and challenge (rather than threat). Hardy individuals who possess this set of interrelated beliefs are able to appraise "...potentially stressful situations as less threatening, thus minimizing the experience of distress" (Bonanno, 2004, p. 25). 
Based on Bonanno's (2004) assertion that the personality trait of hardiness represents one of many pathways to resilience under stress, it may be helpful to evaluate the effectiveness of interventions that enhance the attitudes, coping strategies and interaction patterns of hardiness. This endorsement led Maddi (2005) to conclude that "personality hardiness is emerging as a pattern of attitudes and actions that helps in transforming stressors from potential disasters into growth opportunities" (p. 261). Hardiness has been found to decrease strain and illness through the increased likelihood of engaging in healthy behaviors (e.g., coping strategies) rather than unhealthy behaviors (Maddi \& Kobasa, 1984). Moreover, Khoshaba and Maddi (2001) developed a hardiness training program based on theory, research, and practice that has shown student improvement in grade point average, increase in college retention rates, and health and improved job performance in working adults for individuals who completed the training.

Protective and risk factor identification provides researchers with the distinction among children who have a healthy adaptation from those with a less healthy adaptation to adversity (Werner \& Smith, 1977). In their extensive review of 25 years of resiliency research, Masten and Coatsworth (1998) identified several protective factors that have shown the ability to alter and enhance positive development and well-being in youth. For example, these researchers identified good intellectual functioning, high self-esteem, connections to extended family networks, and attendance at effective schools as protective factors or qualities of resilient youth. Understanding the effects of protective factors on an adolescent's developmental trajectory supports the design of a curriculum which may provide adolescents with the opportunity to enhance their hardiness attitudes which will in turn mediate the effects of existing risk factors. These risk factors include 
impulsivity and avoidance coping (Cooper, Wood, Orcutt, \& Albino, 2003). This evidence-based hardiness curriculum will attempt to provide adolescents with an intervention supporting the development of resilience.

\section{Statement of the Problem}

Researchers have attempted to study the factors that contribute positively to an adolescent's development (Masten \& Garmezy, 1985) and have identified certain constructs that provide the protection required to buffer the individual from potentially damaging effects of these risks (e.g., stress, illness, poverty, parenting). Some of these protective factors include internal locus of control and healthy positive relationships with adults (Masten \& Coatsworth, 1998). Young adults who have a positive relationship with at least one adult fare better than young adults who do not have positive relationships with adults (Luthar et al., 2000). Protective factors can be found in the family (Blum et al., 2000; Masten, 2001), the community and the individual (Luthar et al., 2000; Masten \& Coatsworth, 1998).

Although there is a plethora of research documenting the contributions of hardiness in a variety of contexts and different participants (Bartone, 1989; Keane, Ducette, \& Adler, 1985; Maddi, 2002), no studies have examined the underlying constructs of hardiness, self-esteem, and perceived social support before and after a hardiness training program using at-risk adolescent males. Moreover, a relatively large proportion of published studies have been conducted with adults. This makes the generalizability of results from these studies to adolescents inconclusive.

The identification and promotion of individual personality characteristics in adolescent males that may counterbalance or minimize the potential risk factors is one 
viable option educators can use to support the development of resilience (Masten, 2001). Research exploring gender-differences in hardiness have found that males are more vulnerable to various psychiatric problems (Sheppard \& Kashani, 1991). In addition, the control component of hardiness seems to moderate the stress/illness relationship among men, making it a better predictor of the stress/illness relationship for men versus women (Caldwell, Pearson, \& Chin, 1987). Thus, promoting the development of resilient or hardy functioning in male adolescents could serve to prevent the need for future intervention (Luthar et al., 2000; Maddi, 1999).

Although schools are recognized as a central source for promoting children's mental health, according to the U.S. Department of Health and Human Services (1999), well below $50 \%$ of children with mental health disorders receive adequate treatment to address their needs. When the mental health needs of children are not met, there are profound effects that lead to poor health outcomes when children become adolescents and adults. Moreover, the effects can jeopardize the safety of families, communities, and in some cases, society at large (Sheridan \& Gutkin, 2000). Therefore, understanding the effectiveness of a hardiness education program with adolescent males seems to be a local priority for promoting the development of hardy functioning males.

The theory and practice of prevention is based largely upon research related to developmental psychopathology and resilience (Cicchetti \& Toth, 1998; Masten \& Coatsworth, 1998). However, research related to the development and validation of intervention strategies has been limited by its narrow focus. Because little is known about the efficacy of hardiness training with adolescents in school settings, there is a need to evaluate the personality trait of hardiness with those who are likely to experience 
stressors because of their daily habits. The evaluation of such an approach can help to inform decisions about how to support the healthy development of adolescent male needs after experiencing significant life stressors and being exposed to a training curriculum that helps to transform stressors from potential disasters into opportunities for growth. Statement of Purpose and Research Question

The purpose of this study is to compare measured levels of hardiness attitudes, self-esteem and perceived total social support between an experimental and a control group following an 8-week hardiness training. The control group did not receive the hardiness training. The overall research question is: will males who attend an 8-week hardiness training experience significant changes in measures of hardiness attitudes, selfesteem and perceived total social support when compared to a control group? 


\section{Definition of Terms}

The following terms and definitions will be used throughout the study:

\section{Challenge-}

Theoretical: One of three components of hardiness; implies that the activities are viewed as the motivating factors in learning. A person with a strong self-perception of challenge will more often than not see satisfaction in the new activity, rather than in a routine experience (Kobasa, 1979b).

Operational: The quantitative score obtained on the Personal Views Survey$3^{\text {rd }}$ Edition, Revised (Maddi et al., 2005).

\section{Commitment-}

Theoretical: One of three components of hardiness; refers to experiencing activities as interesting and enjoyable. A person with strong commitment will tend to get involved in activities rather than become alienated (Kobasa, 1979b).

Operational: The quantitative score obtained on the Personal Views Survey$3^{\text {rd }}$ Edition, Revised (Maddi et al., 2005).

\section{Control-}

Theoretical: One of three components of hardiness; refers to viewing activities as a matter of personal choice and initiative. Persons identified as having strong control will less often see him/herself as a victim and believe that life events are the outcome of one's actions (Harris, 2004; Kobasa, 1979b). 
Operational: The quantitative score obtained on the Personal Views Survey $3^{\text {rd }}$ Edition, Revised (Maddi et al., 2005).

\section{Hardiness-}

Theoretical: A strong sense of self in the world; a personality variable composed of three components: commitment, control and challenge (Kobasa, 1979b).

Operational: The overall quantitative score obtained on the Personal Views Survey - $3^{\text {rd }}$ Edition, Revised (Maddi et al., 2005).

\section{Self-esteem-}

Theoretical: The evaluation which individuals make and customarily maintain with regard to themselves, expressed as an attitude of approval or disapproval (Coopersmith, 1967).

Operational: The overall quantitative score obtained on the Rosenberg Self Esteem Scale; A score of 15- 25 is considered normal, while less than a score of 15 suggests low self-esteem (Rosenberg, 1967).

\section{Social Support-}

Theoretical: An individual's perceptions of general support or specific supportive behaviors from people in their social network, which enhances their functioning and/or may buffer them from adverse outcomes. Five sources of social support are considered (parent, teacher, classmate, close friend and school). The content of social support can be divided into 4 types: Emotional, Instrumental, Informational and Appraisal Support (Malecki \& Demaray, 2002). 
Operational: The overall quantitative score obtained from the parent, teacher and close friend subscales as well as the individual scores on the types of support (emotional, instrumental, informational and appraisal) on the Child and Adolescent Social Support Scale (Malecki, Demaray, \& Elliott, 2000).

Organization of Study

Chapter I contains the introduction, statement of the problem, statement of purpose, research questions and the definition of terms. Chapter II contains the review of literature, specific literature concerning the risk and protective factors that have been investigated, the literature relevant to resiliency and hardiness, and a general review of male adolescent development. Chapter III contains the methodology, including research design, research hypotheses, the participants used in the study. Chapter IV contains the results and Chapter V contains the discussion section as well as limitations of the study and implications for future research. 


\section{CHAPTER II \\ REVIEW OF LITERATURE}

Hardiness as a construct and the effectiveness of hardiness training have been studied using populations in various settings. The purpose of this study is to describe the potential effectiveness of an 8-week hardiness training program attended by ninth grade adolescent males attending an alternative high school. This study will attempt to demonstrate that by receiving hardiness training, adolescent males will provide higher ratings on measures of hardiness attitudes, self-esteem and perceived social support both in the short- and long-term. The following literature review is organized according to each of these variables, a brief overview of resiliency literature, and a summary of adolescent development.

Resilience

When youth are faced with psychological difficulties, some seem to flourish, while others do not appear to function as well. The variables which promote resilience (i.e., protective factors) became recognized initially through the work of Werner and Smith (1982). They conducted a longitudinal study (1982) which examined a sample of high-risk children and youth $(N=698)$ from Kauai over a span of 20 years of their lives. These investigators examined the biological, social and psychological factors that were predictive of both coping problems and resiliency in this sample of children. These "sources of strength" were then examined to search for the pathways that lead these children to success when faced with potential risk factors (Werner \& Smith, 1982). 
Gender differences in vulnerabilty and resiliency were also investigated. For adolescents, Werner and Smith (1982) found that by age 18, almost three times as many boys $(n=72)$ than girls $(n=26)$ had records of serious delinquencies. By age 10 , the stressful childhood events that discriminated between males with and without coping problems and females included: older sibling leaving home, inconsistent employment by the mother, marital problems, absence of the father and/or replacement by a stepfather. For females, significant life events associated with childhood learning and/or behavior problems included: serious illness of the father, death of a brother, and having a handicapped sister with serious learning and/or behavior problems (Werner \& Smith, 1982). A need for long-term mental health services (greater than 6 months), remedial education and a physical handicap (by age 10) were found to be the most significant predictors of serious mental health problems in late adolescence for males. For females, a combination of a learning disabilty with a need for mental health services and a physical handicap (by age 10) was found to predict serious mental health probems in late adolescence (Werner \& Smith, 1982).

The resilient adolescents who were faced with four or more risk factors by age 2 but managed to cope successfully had similar personality attributes that differentiated them from the adolescents who had difficulty coping with problems (Werner \& Smith, 1982). The California Psychological Inventory (CPI) (Gough, 1969) and the NowickiStrickland Locus of Control Scale (Nowicki \& Strickland, 1973) were the instruments used to assess various personality characteristics within this cohort. The CPI contains four subscales that measure: (1) poise, ascendency, self-assurance, and interpersonal adequacy; (2) socialization, maturity, responsiblity, and interpersonal structuring of 
values; (3) achievement potential and intellectual efficiency; and (4) intellectual and interest modes (Gough, 1969). The Nowicki-Strickland Locus of Control Scale measures the degree to which a person believes that a "behavioral event" is caused by a person's own action (Nowicki \& Strickland, 1973).

On the CPI, the resilient adolescents (both males and females) scored significantly higher in the areas of responsibility, socialization, communality, achievement via conformance and femininity. Adjectives used to describe the individuals who scored high in the aforementioned areas include: "...adaptable, efficient, organized, sincere, unassuming, enterprising, idealistic, intelligent, resourceful, confident, energetic, humorous, rational, realistic, strong, emotionally responsive, gentle, nurturant, and sensitive" (Werner \& Smith, 1982, p. 88). The results from the Nowicki Locus of Control indicated that late in adolescence, the resilient youth were found to have a greater internal locus of control. This cohort of youth also expressed a greater desire to "improve themselves psychologically" (Werner \& Smith, 1982, p. 154).

Other studies have found that the characteristics of resilient children and adolescents fall into three categories: individual, family and extrafamilial (Masten \& Coatsworth, 1998). Individual characteristics include high self-esteem, good intellectual functioning, being sociable and having an easygoing disposition. Families have been found to provide protection from adversity in the form of close relationships to caring parents, authoritative parenting, warmth, socioeconomic advantages, and connections to extended supportive family networks. Outside of the family, the extrafamilial characteristics that promote resilience in children and aolescents include bonds to 
prosocial adults and prosocial organizations and attending effective schools (Masten \& Coatsworth, 1998).

Being identified as resilient, however, does not indicate an absence of a reaction to life's stresses. To believe that having the "right" number and combination of protective factors will ultimately protect a child is incorrect. Children who have been identified as resilient differ from others on internalizing symptoms. They have reported higher scores on depression and anxiety scales than children who were also high in competence but from low-stress backgrounds (Luthar, 1991). They are considered resilient in that they are successful in their day-to-day functioning based on societal expectations (Luthar, 1991). This finding suggests that although personality attributes can moderate life's stresses among youth, there is a need to provide all youth with strategies to handle the daily problems, potentially promoting not only resiliency, but emotional health as well.

\section{Hardiness Construct}

The adolescents's ability to handle a stressful conflict is related to the adolescent's hardiness (Masten \& Coatsworth, 1998; Sheppard \& Kashani, 1991). Hardiness has been identified as a potential pathway to resilience (Bonanno, 2004), and refers to an individual personality characteristic that influences one's performance, coping, conduct, morale, stamina, and health (Maddi, 1999).

Hardiness was first conceptualized in 1979 in a study that looked at 670 middle and upper-level executives at Illinois Bell Telephone (Kobasa, 1979a). These executives were experiencing a tremendous amount of perceived stress in their work environment as a result of its parent company, AT \& $\mathrm{T}$, being forced to deregulate and divest its subsidiaries (Maddi, 2002). The participants were given two questionnaires: (1) 
addressing stressful life events; and (2) capturing the physical symptoms of stress. The results indicated a group of employees who were high in stress and experienced fewer mental and physical illness symptoms, while the other group was high in stress but experienced more symptoms of physical illness. A subsample was selected from each group and completed a personality questionnaire. Results of the personality questionnaire indicate that high stress/low illness individuals show significant differences from the high stress/high illness individuals in the areas of commitment to self, sense of vigorousness about life, sense of meaningfulness, internal locus of control, and an ability to deal with external life stresses without seeing them as personal threats. Findings suggest that certain personality traits moderate the stress-illness relationship, allowing an individual to remain healthy while under stress. This personality trait has come to be known as hardiness (Kobasa, 1979a).

A discussion of the early development of hardiness attitudes in childhood is germane because most of the early studies focused on middle-aged American executives and professionals. According to Kobasa and Maddi (1977), the ideal condition of hardiness development is when a young individual must navigate his or her way through the difficult period of childhood into adolescence, which is marked by significant social and biological changes. An important ingredient that fosters the resulting growth of hardiness is when a family responds to frequent stressful events by developing compensatory strategies that become an organizing principle (Maddi, 2002).

Figure 1 depicts the hardiness model of vulnerability and resistance factors influencing well-being. As can be seen by Figure 1, the individual inherently has his or her own vulnerabilities (or weakest links). As stressful circumstances put a strain on the 
individual, there is a potential for a breakdown (e.g., behavioral, mental, or physical). Hardy beliefs motivate the individual to react to the stresses with hardy coping (e.g., being decisive). Hardy beliefs also promote the use of social support and healthy practices. Furthermore, by practicing the "hardy skills" (i.e., in a hardiness training program) the hardy attitudes can deepen, perpetuating the process (Maddi, 2002).

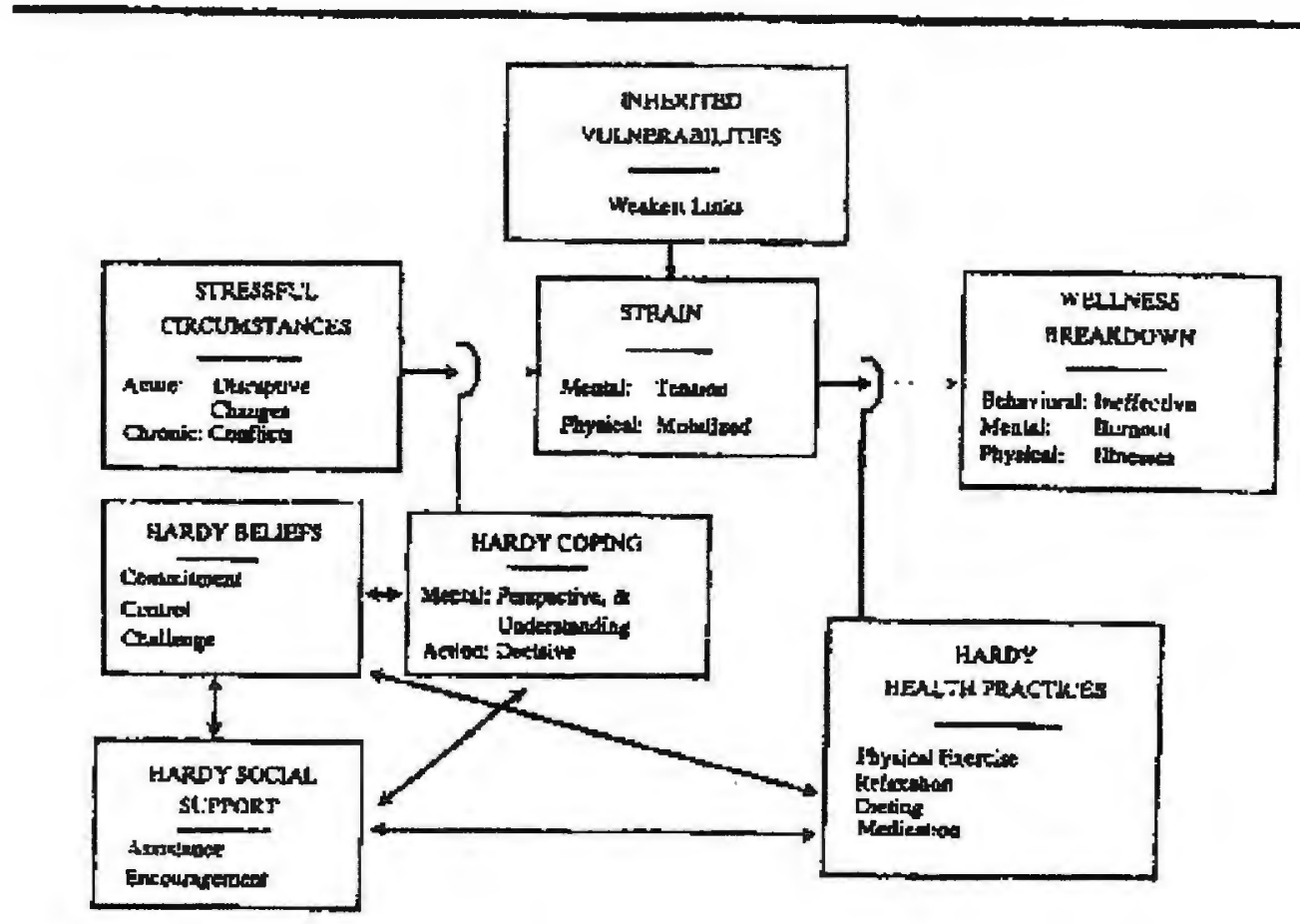

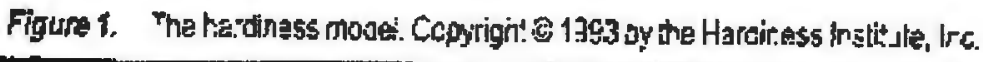

A review of studies on hardiness suggests that only a few address the theoretical relationship it has with mental health. More recently, Maddi and Khoshaba (1994) surveyed 158 undergraduate students at a public university to develop a better understanding of negative affectivity (i.e., general tendency or bias to respond with 
unpleasant emotion and pessimism) and the purported role of hardiness to decrease stress related symptoms. These participants completed the Personal Views Survey and the Minnesota Multiphasic Personality Inventory (MMPI) as measures of hardiness and psychopathological tendencies, respectively. There was a pattern of significant inverse relationships between hardiness and negative affectivity. These findings suggest that hardiness is a negative predictor of MMPI scores on Depression, Paranoia, Psychasthenia, Schizophrenia, Social Interest, Anxiety and Dependency scales, when the effects of negative affectivity are controlled. These and the other studies suggest that hardy attitudes protect against stress-related breakdowns, self-limiting or regressive coping (i.e., using denial or avoidance in stressful circumstances), and mental illness. Furthermore, the pattern of negative relationships between hardiness and the negative affectivity scores suggests that for hardiness it is an indicator of mental health, as well as a positive predictor of ego strength. Subsequent studies have also found significant inverse relationships between hardiness and measures of depression and anxiety (Allred \& Smith, 1989; Drory \& Florian, 1991; Funk \& Houston, 1987; Rhodewalt \& Zone, 1989).

In order to explore some of the factors that were potentially important in the development of hardiness attitudes and identify some of the psychosocial correlates to hardiness, a sample of adolescents from Newfoundland $(n=317)$ enrolled in grades 7-12 participated in a study. Hannah and Morrissey (1991) administered a 20-item hardiness scale and a happiness scale. Using a multiple regression analysis, sex, age, religion, happiness and grade were used as the independent variables to predict hardiness. These five variables were deemed as components in the development of hardiness and all of 
them were successfully entered into the equation. Additionally, a path analysis was conducted to determine possible paths of causality. Two possible paths of causality emerged from the study. The first path was through age and grade. The second pathway was through religion, sex and happiness. Both standardized coefficients were significant and, "greater than the coefficients of the single variables regressed on hardiness scores" (p. 341). Further interpretation of the exploratory path analysis implies that hardiness was shown to increase with both the age and grade. One potential conclusion is that success in school could be related to the increase in one's hardiness attitudes, while failure in school would lead to a decrease in hardiness attitudes. Although the findings of this study shed some light on the causal pathways of hardiness, more research is needed to develop a better understanding of the complex relationship between hardiness, school success and religiosity (Hannah \& Morrissey, 1991). In summary, this research has provided some preliminary support for the hardiness model proposed by Kobasa (1979a). Furthermore, the results suggest the need for more research into the factors that may contribute to our knowledge about how resilience under stress is fostered to the development of hardiness attitudes (e.g., self-esteem, social support) in adolescence.

\section{Resilient Males: Self-esteem and Social Support}

A study on self-esteem throughout the lifespan showed there was no significant difference between self-esteem levels for boys and girls (ages 9-12) (Robins, Trzesniewski, Tracy, Gosling, \& Potter, 2002). During adolescence, however, girls' selfesteem is found to decrease twice as much as boys' self esteem. This difference has been attributed to puberty and the maturational differences that exist during this time period for females and males and the transition from grade school to junior high school (Robins 
et al., 2002). Maintaining higher levels of self-esteem, however, can serve as a protective factor, and it is therefore important to understand these differences in males and females and how educators may impact the students at this developmental stage.

High levels of self-esteem in adolescents combined with high levels of perceived social support have been shown to "moderate the relationship between daily hassles and physical symptoms," (McNamara, 2000, p.18). Furthermore, an adolescent's social support combined with positive health practices have been found to be correlated as well as self-esteem and positive health practices (Yarcheski, Mahon, \& Yarcheski, 2003). An adolescent's self-esteem and his or her relationship with his or her parents has been shown to also have direct predictive power on happiness (Cheng \& Furnham, 2003), while adolescents who report having experienced serious problems tend to have poor self-esteem (Porteous, 1981). According to McNamara (2000), "Psychological and social factors, such as social support, perceptions of control and personality factors, exert a direct and indirect influence on both the short-term and enduring outcomes of stress" ( $p$. 17).

Social support is an important factor related to self-esteem. Harter (1993) designed an instrument that looked at four areas of potential support for adolescents (i.e., parents, teachers, classmates and close friends). Through her research, she found a significant positive correlation between perceived social support from others and selfesteem.

Social support has been identified as a negative indicator of depression, anxiety, and withdrawal, while it serves as a positive indicator of self-esteem, leadership and social skills (Demaray \& Malecki, 2002). It serves as a protective factor by providing the 
adolescent with advice in coping with problems or stressors and can provide an outlet, allowing the adolescent to utilize effective coping strategies (McNamara, 2000).

Hardiness has been found to be a mediator of the relationship between social support and outcome. These outcomes include depression, life satisfaction, and self-reported health (Wallace, Bisconti, \& Bergeman, 2001).

Werner and Smith (1982) found that resilient adolescents were more likely to seek and receive help from a greater number of informal sources of support (e.g., peer friends, siblings, cousins, older friends, older relatives, parents, ministers, and teachers). An interesting gender difference emerged between the resilient males and females, as the resilient males used their teachers as a source of support more often than the resilient females (Werner \& Smith, 1982).

In a study examining the relationship between perceived social support and (mal)adjustment indicators, Demary and Malecki (2002) used an ethnically diverse sample of children enrolled in 6th through 8th grade, with a majority of the participants classified as low income. The Child and Adolescent Social Support Scale (CASSS) was used in conjuction with a behavior assessment scale to explore the relationship between these two indicators. Significant positive relationships were found between overall social support and positive adjustment indicators, while significant negative relationships emerged for social support and (mal)adjustment indicators. Parent and classmate support revealed a strong positive relationship with clinical and maladjustment composite and interpersonal indicators, suggesting that the more support from these sources a chlid receives the better his or her school adjustment. Parent, classmate and close friend support were found to have a significant positive relationship with personal adjustment 
indicators (e.g., interpersonal relations). Teacher and parent support were found to predict positive school adjustment. The findings suggest the reinforcement of positive, supportive parental relationships, as well as the fostering of friendship and the influence of the student-teacher relationship (Demaray \& Malecki, 2002). In conclusion this topic deserves further research exploring the relationships among variables in a representative sample of children and adolescents.

\section{Adolescent Development}

Normal adolescence involves a period of biological, developmental, psychosocial and cognitive development. Biologically, adolescence is a period of "rapid skeletal and sexual maturation...(but) is not a single sudden event. It is part of a gradual process" (Santrock, 1999, p. 339). Testosterone, the hormone associated with most of the physiological changes in males, aids the adolescent in the areas of growth (both height and weight), as well as in the development of the primary sex characteristics (e.g., nocturnal emissions) and secondary sex characteristics (e.g., voice changing, body hair, muscle development). These changes are related to the hormones within the adolescent and can be seen in adolescents at various ages (Manaster, 1989; Santrock, 1999). Because puberty can occur at different ages in both males and females, there is evidence that this can impact certain aspects of young men, in particular. There is some evidence that suggests that early maturing males have been shown to have advantages over latematuring males in the domains of self-confidence and independence (Jones, 1957; Mussen, 1957). On the other hand, late-maturing males in adulthood are more insightful and have more social initiative (Jones, 1957). 
Simultaneously, as the male adolescent undergoes biological changes, there are many developmental tasks that the adolescent is faced with as he attempts to emerge from childhood and set a course for adulthood. Broadly these tasks involve work, friendship and love (Manaster, 1989). Specifically these tasks include maturing relations with peers of both sexes; acquiring a feminine or masculine social role; accepting the body's changing physique; striving for independence from adults; planning for the future; developing values; transitioning to secondary school and achieving academically; involvement in extracurricular activities; forming a sense of self; and being responsible (Manaster, 1989; Masten \& Coatsworth, 1998). As children and adolescents make their passage to assume adult roles and responsibilites, their developmental course is usually influenced by the demand and pressures of the environment, culture and patterns of socialization. Therefore, it seems important to briefly highlight the pertinent literature on adolescent development as it relates to personality, cognitive and emotional development in the midst of stressors.

Erikson's eight psychosocial stages covering the lifespan are each identified by the psychosocial crises or conflicts that emerge (Miller, 1993). Within each crisis, Erickson described both the positive and negative outcomes that may result as the individual progresses through the stage (Cole \& Cole, 2001). In adolescence the psychological crisis is called identity and repudiation versus identity diffusion (Miller, 1993; Santrock, 1999). Trust, autonomy, initiative and industry are all components that have and continue to contribute to the identity of the child who is now emerging as an adolescent (Cole \& Cole, 2001). The new identity is greater than the sum of all of the aforementioned components and reconfigured to meet the new pressures that accompany 
this period in an adolescents lifespan. In this stage, the physiological changes (e.g., a new voice, larger body, facial hair) have created a body that may seem familiar at times, and unfamiliar at other times (Miller, 1993).

Adolescence is also a time when males are provided with the opportunity to try out different roles. There are increasing pressures to gain employment, plan for an educational future, or develop an athletic career. The decisions made during adolescence can hold irreversible consequences for adulthood (McNamara, 2000). If the adolescent is successful in reconfiguring previous identifications or components to meet these new pressures, according to Erikson, he or she can then form a "core self." If the adolescent is unable to integrate the identifications or roles, a core self does not develop. Erikson refers to this as "identity diffusion" or role confusion. According to Erikson, success at this stage can lead to the next psychosocialcrisis in young adulthood (Cole \& Cole, 2001).

Piaget's theories in cognitive development can be applied to adolescents as well. Piaget's view that knowledge is biased can help us understand why children or adolescents can filter experience. This filter can at times prevent the developing child or adolescent from having a clear picture in his or her mind that aligns with reality (Manaster, 1989; Miller, 1993). According to Piaget, between the ages of 12 and 19 years, an adolescent begins to develop his or her logical and abstract thinking (i.e., formal operational reasoning). The adolescent no longer accepts concrete experience, but thinks about other hypotheses that may explain certain things as he or she tries to reason about the other abstract propositions (Santrock, 1999). Moreover, adolescents can also imagine their future and the various possibilities that await, while attempting to try out these future possibilities through employment or membership in clubs. Their hypotheses 
about the outcomes of the experimental role assumptions may or may not be positive. The adolescent also tends to develop a keen sense of adult hypocrisy, remaining egocentric (Cole \& Cole, 2001).

When an adolescent is unable to integrate identities, a crisis emerges. According to Marcia (1980), this adolescent has not been able to experience active commitment in a belief or occupation and is easily influenced by others. In addition, the adolescent will often change his or her beliefs (Marcia, 1980). Furthermore, the uncertainty about sexual orientation can influence this crisis, causing teens to hide their identities, isolate themselves, and protect themselves from stigmatization (Harrison, 2003).

As discussed earlier, adolescence is a time of new experiences and pressures. As the adolescent male experiences puberty, he is also asked to meet developmental and social tasks. This is a time of confusion, learning, and growth, all of which can be debilitating for male teens or seen as an opportunity for growth (Sameroff, 1993). The stress that adolescents face can be dealt with in healthy ways. This stress or resulting conflict can be seen as a stimulus that provides the needed movement of an adolescent's social growth towards social maturity. By learning to understand the meaning underlying this conflict, adolescents can learn to become competent at filtering and managing the emotions before the emotions start managing the adolescent. White (1989) discusses three major conflict areas that adolescents face: internal psychological, situational and social/interpersonal. Internal psychological conflicts result from unresolved past events in the younger developmental stages, conflicts between the past and the present and conflicts between the present and the future. Situational conflicts result from sudden loss or situations that cause the adolescent to realize that things may be out of their control. 
Social/interpersonal conflicts are a result of personal conflicts with peers, family members and society (White, 1989).

Erikson's theory of psycholosocial crisis in adolescence (identity versus role confusion) is based on the aforementioned conflicts that the adolescent must integrate and overcome in order to emerge with an identity (White, 1989). Adolescents will attempt to protect themselves through this period of new and intense conflict by developing protective strategies (i.e., defense mechanisms). Adolescents work to minimize the conflict by getting angry, relaxing, venting, and crying. The defense mechanisms that are utilized by the adolescent are in a sense helping to keep the adolescent in balance. Some examples of defense mechanisms include: repression (i.e., unconscious filtering out of unwanted drives), denial, rationalization, intellectualization (i.e., handling the stress in an intellectually neutral manner), projection, and acting out (White, 1989).

While unhealthy coping behaviors (e.g., smoking, drinking and substance use) are generally adopted during adolescence, mental health problems in adulthood have also been shown to begin during adolescence (McNamara, 2000). Therefore, gaining an understanding of the period of adolescence provides important information regarding their psychological health and how life stressors can impact their ability to use resources to cope with life change. Additionally, examining adolescence underscores the point that because children have a diverse set of vulnerability and protective systems at different ages and points in development, there is a great deal of interplay between the child and the environment (Masten, Best, \& Garmezy, 1990). Moreover, although adolescents are more advanced than younger children at adapting to changes in their environment, they are equally vulnerable "to the experience of loss or devastation concerning friends, faith, 
schools, and governments" (Masten \& Coatsworth, 1998, p. 212). This highlights the need for examining intervention techniques that can help to influence competence in the school years.

\section{Hardiness Training}

According to Maddi (2002), in the period following the deregulation and divestiture of $\mathrm{AT} \& \mathrm{~T}$ and its subsidiaries, IBT requested support to help their managers cope with the stressor of this challenging event. This collaborative effort led to the development of an early version of hardiness training. Early versions of this training approach, a 15-weekly session program, emphasized the teaching of coping techniques and use of feedback to bolster their hardy attitudes.

One study that evaluated the effectiveness of hardiness training used a population of high-risk undergraduate students in their first semester of college (Maddi et al., 2002). Specifically, the study investigated hardiness training and its effect on retention rates and grade-point averages. Forty students were selected for the hardiness training group, and 53 students were chosen for the control group. Both groups were mostly Caucasian, unmarried, and approximately 20-years old. Inclusion in the study was based on the participants meeting at least one of the U.S. Department of Education criteria for being high-risk. These risks included: (a) showing a history of difficulty in reading, writing or mathematics; (b) first generation immigrant status; (c) having no role model at home with a college degree; (d) minority status; and (e) having a disability. Following an ANOVA using gender, age, ethnicity, marital status, parental education level, GPA, or college credits completed as independent variables, no between-group differences were found (Maddi et al., 2002). 
The hardiness training was offered as a college course, meeting twice a week for 1 hour. The textbook used by the facilitators of the course was the HardiTraining workbook developed by Khoshaba and Maddi (2001). The participants in the course were directed to identify stressors, coping strategies and work to design a plan of action that would enhance hardiness attitudes. The control group was divided and enrolled in one of two student-enrichment courses. One course emphasized time management, study skills and remedial work; while the other course emphasized leadership training. Pre- and posttests were administered using the Hard Survey III-R (Maddi \& Khoshaba, 1999).

Findings from the study (Maddi et al., 2002) indicated that the participants in the experimental group showed a statistically significant decrease in stress, strain, regressive coping, and a lower vulnerability index score. In addition, the experimental group had higher scores on measures of hardiness attitudes, transformational coping, work/school support, family support, resistance and wellness scores. The control group showed statistically significant increases in transformational coping and a decrease in total resistance and total vulnerability indices. The experimental group overall, showed a larger decrease in strain and regressive coping and a larger increase in hardiness attitudes, work support, resistance, and wellness indices than the control group.

One year after the courses were completed, grade point averages and the rates of retention were compared between the two groups. Findings indicate that the experimental group had significantly higher grade point averages than the control group. The experimental group's retention rates were higher (73\%), although this was not significantly different from the control group (55\%). Overall, implications for this study suggest that hardiness training has an influence on hardiness attitudes and coping. The 
students were able to learn the skills required for adaptive problem solving rather than using maladaptive techniques, such as denying or being overwhelmed by them (Maddi et al., 2002).

\section{Rationale for a Group Intervention}

Few empirical studies of group psychotherapy with adolescents have appeared in the literature (Glodich, 1999). From a basic clinical context, group work with adolescents has been a popular treatment modality. Both the development of cognitive behavioral therapy and Erickson's work in the area of developmental tasks of adolescents have supported the implementation of a time-limited group treatment intervention with adolescents (Pollock \& Kymissis, 2001). Others have stressed the importance of educational groups as a method which allows the development of adolescent leadership and skill acquisition in a safe and realistic environment (van Linden \& Fertman, 1998). Research Question

The research question that will be investigated is as follows: Do urban adolescent males within an experimental group experience more or less changes in their measured levels of hardiness attitudes, self-esteem and overall perceived total social support after receiving the eight weeks of hardiness training in comparison with a control group that does not receive the hardiness training? 


\section{CHAPTER III}

\section{METHOD}

\section{Sample Size and Recruitment}

A non-probability sampling technique (i.e., convenience sampling) was utilized. In convenience sampling, the selection of participants from the population (i.e., the schools included in the study) is based on easy availability and accessibility. There are 12 ninth grade advisories in total, located at three different campuses: the Public Street Campus (which has four small schools: Justice, Unity, Equality and Liberty), the Shepard Building and Peace Street. Students are randomly assigned to each of these 12 advisories. For this study, the ninth grade males at Peace Street, the Justice Building and the Shepard Building were chosen for the experimental group, as these three schools are the most isolated from one another. The ninth grade males from the remaining three schools were placed in the control group.

\section{Participants}

The criteria for inclusion in this study included: (1) attendance at the Met School, (2) being in the ninth grade, and (3) being male. Archival data were collected from the Metropolitan Regional Career and Technical Center (Providence, RI). Institutional Review Board approval was granted as an exempt review (see Appendix A) as the study had begun under IRB approval from Rhode Island Hospital in the summer of 2005. The study began with 71 participants who were ninth grade males. All 71 participants completed a pre-test. There were 41 participants in the experimental group who began the hardiness training and the control group had a total of 30 males not receiving the hardiness training. Of the 71 participants, two students from the experimental group left 
the Met in the middle of receiving the hardiness training. One student had a medical emergency and was unable to complete the posttest. Three students from the control group attended fewer than the required six sessions. Difficulty completing the anonymous code correctly prevented 14 participants from being included in the study as their preand posttests were unable to be matched for a comparison. At the time of data analysis, 51 male students were identified from 12 advisories as participants for this study: the experimental group $(N=23)$ and the control group $(N=28)$. Ages ranged from 13 to 16 , with a mean age of 14.2 years. The sample was comprised of students from six ethnic groups: 15 Latino/Hispanics (29.4\%); 12 Bi-racial (23.5\%); 10 African-Americans (19.6\%); 9 Caucasians (17.6\%); and two Asians (3.9\%). Three (5.9\%) participants did not report their ethnicity. In general, the Met School enrollment is $73 \%$ minority, with approximately $39 \%$ of the students of Hispanic descent, $32 \%$ African-American, and $2 \%$ Asian/Pacific Islander.

Participants from the experimental group received an 8-week treatment and the males from the remaining three schools were considered members of a control group that did not receive the hardiness training. All ninth grade male students who participated in the study received a pretest measure. Posttest measures were collected from both groups one week following the termination of the intervention for the experimental group.

\section{Setting}

Providence, Rhode Island is New England's second largest city, with a population of 173,618 . Providence experiences the problems of many older cities in that it has one of the lowest median household incomes $(\$ 26,867)$ and the highest number of food stamp participants $(32,791)$ than anywhere else in Rhode Island (Jordan, 2004). Providence 
ranks at or near the top in percentage of single-parent families, births to teens, unemployment among young adults, substance abuse, juvenile crime, and school dropouts (Rhode Island Kids Count Factbook, 2000).

Within the city of Providence is the Metropolitan Regional Career and Technical Center ("the Met School"). The Met School is a state-operated "alternative" public high school that opened in 1996. Seventy-five percent of the student body originates from Providence, while the other $25 \%$ is from other cities and towns throughout the state of Rhode Island.

The Met School is an innovative student-centered high school which was designed to create personalization and real world learning. The Met School is deliberately small in order for students and faculty to know one another well in this environment. The studentteacher ratio is 15:1; each student is assigned the same advisor for all 4 years. At the Met School, students are encouraged to explore both personal issues and passions and are usually willing to participate in offerings at the school. Student passions are encouraged within the walls of the school, but also at the required internship which the student attends every Tuesday and Thursday under the guidance and supervision of an internship mentor.

The motto of the Met School is, "one student at a time." Each quarter every student develops his or her own learning plan which states his or her learning goals, based on his or her own learning style and interests. Learning goals are based on the following areas: empirical reasoning, social reasoning, personal qualities, communication, and quantitative reasoning. Student projects drive most of the work and are created at the internship site with the student's mentor. 
In the school climate literature, researchers have concluded that the social environment of a school can have a significant impact on the achievement, social adaptation, socialemotional and behavioral adjustment of its students (Brand et al., 2003). A school's climate and how it is perceived by its students can therefore determine how a student adjusts and possibly feels about him or herself. A recent study found that a relationship exists between students' reports of peer self-esteem and depression and their experiences of school climate, "...The nature of the relationship is multidimensional; conditions that are associated with better adjustment include higher peer commitment to academic achievement, prosocial behavior, greater access to teacher ...and lower levels of expsoure to safety problems," (Brand et al., 2003, p. 585). The Met recently completed the SALT survey for the academic year 2003-2004 (Felner, 2004). Sixty-three percent of the students reported that overall, they felt they could talk to a teacher or other staff member about personal or family problems most of the time or always. For this question, the Rhode Island High School State average was $18 \%$. Only five percent reported that being teased or bothered by other students is a moderate to severe problem (compared to the Rhode Island High School State average at 10\%). Eighty-five percent of the students surveyed felt that their teachers took a personal interest in the students (versus $30 \%$ for the state average). Approximately $75 \%$ of the students reported having a sense of belonging in the school (compared to the state average of 40\%) (Information works! 2005 measuring Rhode Island schools for change: State report card, 2005).

\section{Instruments}

Data for this study was initially obtained by the Rhode Island Injury Prevention Center. They used existing standardized measures. The research literature on hardiness, 
self-esteem, and social support was surveyed to identify the instruments used for measuring these variables in an adolescent population. The following tools were used to measure the variables: The Personal Views Survey-III Revised (Maddi, 2002); Rosenberg Self-Esteem Scale (Rosenberg, 1967); and The Child and Adolescent Social Support Scale (Malecki et al., 2000). In the following section there is a description of each measure and its content. Validity and reliability of the scores are discussed as well. The Personal Views Survey-III Revised

The Personal Views Survey-III Revised (PVS-IIIR) has evolved from a 30-item measure into an 18-item paper and pencil measure of total hardiness, perceived control, commitment, and challenge (Maddi, 2002; Maddi et al., 2005). It also contains basic demographic information (e.g., the participant's age, gender, grade, race and living situation). Items are answered using a four point rating scale (Not True At All, A Little True, True, Very True). Each subscale is measured by three positively and three negatively worded items. Internal consistency reliability estimates of the total scale and subscale reliabilities of the PVS-IIIR were found to be .80 (total hardiness); and .66 for control, commitment and challenge (Maddi et al., 2005). This sample size was 678 undergraduate students and 561 working adults.

Maddi (1999) discussed the findings of various studies which have determined that a greater score on the PVSII tends to relate to a greater likelihood for the enjoyment of activities (commitment); a feeling you have chosen them (control); and a sense you are learning through them (challenge). Other studies have found that greater levels of unconditional self regard are significantly related to higher levels of commitment and control (Betz, Wohlgemuth, Serling, Harshbarger, \& Klein, 2001). 


\section{Rosenberg Self-Esteem Scale}

The Rosenberg Self-Esteem Scale (Rosenberg, 1967) is a well-known scale which was designed to measure global feelings of self-worth. The 10-item instrument uses a four point Likert scale (Strongly Agree, Agree, Disagree, Strongly Disagree) to examine, for example, satisfaction with life, positive attitude toward oneself, feelings of uselessness, desire of self-respect and feelings of being a failure. Points range from zero to three. Five of the items are worded positively and 5 are negatively worded. Scoring of the instrument can be done by adding item responses, using reverse scoring for the negatively worded items. Scores range from zero to 30 , with 30 indicating the highest possible score (Rosenberg, 1967). There are no discrete cut-off points to delineate high and low self-esteem. Higher scores reflect higher self-esteem.

A two-week test-retest reliability was found to be .85 (Silber \& Tippett, 1965). Internal consistency reliabilities have been found to be .87 and .89 (Blascovich \& Tomaka, 1991). The coefficient of reproducibility (Rep.) was found to be .92 (Rosenberg, 1965). A Rep. greater than or equal to .90 is considered “.... an arbitrary minimum for a possible inference that one is dealing with a satisfactorily reliable, unidimensional scale" (Wylie, 1974). Convergent validity has been assessed using similar measures. Moderate to strong correlations (.56 to .83 ) have been found (Blascovich \& Tomaka, 1991).

The Rosenberg Self-Esteem Scale has been used to measure self-esteem in males from diverse backgrounds (Dwairy, 2004; Khanlou, 2004). This scale was designed for adolescents and adults (Harter, 1983; Whiteside-Mansell \& Corwyn, 2003) and was used to assess significant changes in self-esteem in the male participants. 
The Child and Adolescent Social Support Scale

The Child and Adolescent Social Support Scale (CASSS) is a 60-item scale consisting of five12-item subscales (Parent, Teacher, Classmate, Close Friend and School) (Malecki et al., 2000). The CASSS is used to measure social support perception and its importance to children and adolescents in grades 3-12. There are four types of support that the CASSS measures: emotional, informational, appraisal and instrumental. Answers are rated on a six point Likert scale (ranging from 1-never to 6-always). The highest possible score is 60 . There are no discrete cut-off points to delineate high and low perceived social support. Higher scores reflect higher perceived social support.

Reliability coefficient alpha's ranged between .89 (Importance Subscale) to .97 (Total Frequency Scale) for its use with high school age students (Malecki et al., 2000). Factor loadings range between .52 to .81 for the five-factors (parent, teacher, classmate, close friend and school). Test-retest reliability after 8-10 weeks $(\mathrm{R}=.78)$ indicated strong internal consistency (Demaray \& Malecki, 2002).

\section{Procedures}

The Rhode Island Injury Prevention Center received IRB approval from Rhode Island Hospital prior to initiation of the groups and/or administration of the surveys in the summer of 2005. Letters of consent were mailed home to all parents of the potential participants. Potential participants included ninth grade males beginning high school at the Metropolitan Regional Career and Technical Center in Providence, RI. All the survey measures were completed anonymously by the participants within the first two weeks of the start of school in the fall of 2005. To facilitate matching of pretest and posttest surveys, the students were asked to generate a unique code on the first page of the survey 
by answering unique questions (e.g., What is the first initial of your main eighth grade teacher?). The use of this code had been approved by the Rhode Island Hospital's IRB. The code and the measures were read aloud to the participants to ensure that reading level is a not a limitation to the participant's understanding of what is written on the measures. This process took no longer than 25 minutes. No forms used in the study contain any identifying information. Measures are to be stored for three years in a locked file cabinet at Rhode Island Hospital.

Three groups then began the week after the survey measures were completed. The groups were co-led by one experienced licensed clinical social worker and a social work intern. Group sessions were structured for each session allowing comparability across the groups.

\section{Intervention}

The Met School has approximately one mental health provider (e.g., social worker) per school and two social interns (Bachelors and/or Masters level). The Met School also has an outside consulting psychologist available twice a week. The consulting psychologist is part of a multi-disciplinary team that meets Mondays and Thursdays from 12:00 to 4:00 PM. This team provides advisors, principals, students and families a place to problem solve, review psychological and academic testing and receive feedback on areas of concern.

After collecting data on the reasons why students were seeing the social workers in each building, it was determined that ninth grade students (both males and females) were having difficulty with both peer and adult relationships. In an effort to alleviate and aid in the adjustment to the small school setting which is based on relationships, it was 
suggested by the Director of Health and Wellness that the mental health staff design a curriculum that could help students learn ways to solve these issues and enhance selfesteem. The hardiness curriculum was then designed by three clinical social workers at the Met School (Maryellen Butke, Lic.S.W., Diana Kurlander, Lic. S.W. and this author) in the fall of 2004 with the idea in mind that the curriculum would be implemented immediately in the ninth grade year (2005) to both males and females starting at the Met School.

There were many thoughts that went into deciding the length of the hardiness curriculum that could potentially maximize the results. The intervention length for this hardiness curriculum was designed to last the equivalent of one quarter at the Met (i.e., eight weeks). Although the intervention for this study began three weeks into the quarter, in the future if the group is repeated, eight weeks of a group could easily be built into a student's learning plan for one quarter. In a semester long hardiness training course that met twice a week for one hour each, hardiness training was shown to influence hardiness attitudes and coping in college students(Maddi et al., 2002). A 10-week hardiness training condition was shown to increase social support and decrease self-reported strain in business managers (Maddi, Kahn, \& Maddi, 1998) Research on group length has shown varied results. Researchers have shown significant results in four group sessions when working with adolescents between the ages of 14 and 18 with skill building in the area of communication and comfort levels when discussing sex with parents (Burgess, Dziegielewski, \& Green, 2005). When optimal group length was determined in a body image prevention program for 121 adolescent boys between the ages of 12 and 13 years, results indicated improved self-esteem and decreased levels of negative affect after two 
sessions (Sanford \& McCabe, 2005). Long-term effects were not discussed. These results support the design of an intervention offering eight sessions.

The curriculum was designed in a manner that would specifically teach both didactically and experientially the concept of hardiness and its three components (i.e., commitment, control and challenge). Each week, the facilitators would begin checking-in with group members about the adjustment in school or other areas of possible concern (approximately 10 minutes). Space and time was provided for the students to vent or ask questions. A weekly snack was provided and distributed within the first 15 minutes. The next 20 minutes was designed to provide the participants with an actual educational component related to hardiness. The final 30 minutes of the group was specifically designed for the experiential activity (e.g., a role play). The concepts that were taught weekly and discussed were reflected upon and brought up various times throughout the entire life of the group.

The following discussion specifically addresses the topics and activities covered in the weekly group sessions. In week one, group guidelines were established based on the input from the group members and the facilitators. Guidelines included confidentiality, respect, appropriate language (i.e., no swearing), and no cell phone use during group. The concept of hardiness was introduced, as well as its components (commitment, control and challenge) and age-appropriate examples for each component. The group members were encouraged by the facilitators to put definitions and concepts into their own words. Journals were handed out to each group member and the group members were told to write down their answer to the question: How do you want to be in the world. Overall, as these were ninth grade students brought together from two separate advisories, 
establishing rapport was a primary objective. When the experiential part of the group was discussed, the group was told that there was a role play previously designed that would emphasize hardiness and its components as displayed in a scene between two students. The group members were told that in the upcoming weeks, their own personal stories could eventually be used if they felt comfortable sharing. The goal of the activity was to highlight misperceptions and their influence on situations. Participants were assigned the role as either a player in the role play or as an observer.

In week two, groups began with a check-in and members were encouraged to talk about how they answered last week's question (How do you want to be in the world?). The concept of commitment was then introduced. The objective of the group was to enhance each group member's understanding of commitment and help the participants explore who they are committed to and who is committed to them. The idea of social supports and using them when help is needed was discussed. The activity for week two involved asking group members to list members of their social support network on a piece of paper. This list was to include both past and present social supports. The facilitators provided a list of prompts for the group members to use as an idea (e.g., teachers, coaches, parents, etc.). Multiple members asked if labels were appropriate or actual names. The facilitators encouraged the group members to list the people by both their names and labels (e.g., Max, my father). One participant was asked to volunteer to create a social support sculpture. Initially, the facilitators hypothesized that each student would have at least nine members in a social support network. It became evident that some students had only two or three members. The participant chosen was one who had at least four people in his social support network. He wrote each name and label down on 
an individual card and handed the cards out to various other group members. The participant then placed these people in positions of where he saw each person in his life (i.e., if his mom and he have a good relationship, then he would place the person representing his mom close to him). The social support "actors" were then asked to turn their backs to the person volunteering. Scenarios were then read by the facilitators (i.e., You are getting ready for your exhibition. Who are the first people you use?). The volunteer then turned the person/people around who he would use. Other suggestions for scenarios then came from the other males in the group. Ideas like, "You just found out your girlfriend cheated on you. Who do you turn to?" In many of the lists from the participants, it was noted that rarely, if ever, did the males write down their fathers as being part of their social support network. Mothers and grandmothers, however, were commonly mentioned. The purpose of the activity was to help the group members see in writing and in representation who exists in their world as support.

Week three included a continuation of commitment. The objectives included reviewing week two and a discussion began about initiating an effective support system for different situations in each person's life. The participants continued with the work of the previous week, and had the opportunity to openly discuss what happens when we break our agreements with one another and one's self. The importance of staying committed to one's self was emphasized by the facilitators. For the activity, the participants were asked to write a list of "I promise" statements. The group was shown a list of possible promises (e.g., I promise to graduate from high school) and obstacles to following through with these promises (e.g., I cannot wake up on time, therefore I am tardy often). Participants then brainstormed in pairs a list of potential promises and 
obstacles that may effect the fulfillment of their promises. Pairing the group members was counterproductive, as they began having side conversations. The idea behind the pairing of the group members was to provide the opportunity to work with another person. The facilitators then asked the members to work independently. One volunteer was selected and asked to write down at least five possible obstacles to a promise they want to make. The obstacles were passed out to other participants. The participants spread throughout the room like a human obstacle course. The object of the activity was for the participant to face each obstacle and pass through to the next one by verbalizing how they would overcome the obstacle. The volunteer was asked to select a "coach". The coach offered realistic assistance and support as the participant moved through the obstacle course. The question for the journal writing for week three was: What is one promise you can make to yourself this week?

For week four, the group began discussing control. After reviewing the Promise Activity from the previous week, the participants were asked to list situations in which they felt powerless to control the outcome in their life situations (e.g., peer pressure to use substances). The idea for this initial discussion was to provide the group members with the vocabulary needed to describe behaviors involved in gaining a greater sense of control. They were then asked to list alternatives to those situations which would enable them to feel a greater sense of control. The group as a whole decided which situation would be used for a group role play. At this point, roles were assigned to group members. As the role play was being performed, the facilitators would intermittently freeze the action and pose questions to the group members not involved in the role play. For example, "If you were the boy in this scenario, what might you have control over? What 
actions might you do to have an increased feeling of control?" The group was then asked to write about an area in their life where they feel they have no control. Then, using the technique from this week's group, write about the ways they may exercise some control in the area they chose.

Week five was designed to focus on the group members establishing a sense of selfefficacy. The participants continued to explore the ways they can establish a sense of control in their lives. The journal entry for week four seemed a bit difficult, as most group members could write about where they felt they did not have control, but struggled in applying the new techniques they learned in an attempt to exercise control. This seemed to point the facilitators in the direction of discussing different coping styles, as a means of gaining awareness into how each group member copes when feeling out of control. Examples of coping styles were listed on a poster board and discussed (e.g., avoidant coping includes watching TV). The activity for this week involved using three different prefabricated role plays with a listing of the coping styles that should be exemplified within the role play. Groups of four members each were chosen and given approximately 10 minutes to come up with how they would demonstrate the various coping strategies within the role play. The purpose, again, was to visually allow the group members to see these coping strategies in use before their eyes. The journal question for this week was to name the three most common coping strategies you use during stressful situations.

Week six moved the group into the challenge component. The activity idea was introduced through the use of a guest speaker. Because of the timing of the speaker, there was no time to review the previous week's session. Also, because of confidentiality, the 
facilitators did not feel it was appropriate to review the previous week's session with an outsider present in the room. A Met employee was chosen to come and speak about the challenges he has faced in his life and how, with a positive focus, he has managed to move through and navigate these challenges. The participants were allowed to ask the speaker questions after he spoke for 30 minutes. They had numerous questions for the speaker and this question/answer period lasted 20 minutes. With only 10 minutes remaining in the session, challenge was discussed by the facilitators as a positive opportunity for growth, rather than a threat. It was explicitly stated that challenge involves the idea of staying flexible and going in the direction of change, as opposed to resisting or fighting against it. The group was posed questions after the speaker left like, "What were the challenges in the guest speaker's life? How did he overcome these challenges? Would you consider this man to have a positive focus in life?" The difference between positive thinking and positive focus was discussed. For the journal writing piece, the group was asked to write about a situation in their own life involving change and how they would like to view this situation, given the work of challenge.

Week seven began as a complete overview. Using their current situations involving transition and change, participants were asked to talk about (in pairs) how the use of social supports may help them navigate through these changes. It became apparent immediately that the group members were seeing their advisors as supportive. This shift in viewing the advisors in this manner had not been seen up to this point. The participants were asked to work in pairs to address a current situation where they felt powerless to effect change, and brainstorm with their partner ways to have a voice in the outcome of the situation. Their partners became "coaches" helping the other person 
come up with strategies to overcome the challenge. Participants then came back into the large group and shared their experiences. The journal question for this week was: What questions do you have about hardiness - control, commitment, and challenge - or about coping strategies? What three ideas will you take away from this group?

The final group, week eight, became a catchall. The key concepts of hardiness and its three components were reviewed. Generally, the participants checked in about this being the last group, and about what they want to take away from the group overall. The participants were asked to create a future scenario in their lives. Using the technique of visualizing the future in the present moment, they were asked to close their eyes (if they felt safe and comfortable doing so) and imagine the future challenge and envision utilizing the tools and skills learned in the group. Participants were encouraged to continue to seek support from the group to assist them in remembering what they had learned. For the final activity, the group members were each given a prefabricated timeline with certain years listed. The participants wrote down significant experiences from their lives including early childhood (2-3 years old), childhood (5 - starting school), middle childhood (8-9 years old), pre-teen (11-12 years old), and current (14-16 years old). They were asked to write down experiences that they hope to have in the future imagining themselves at high school graduation, in college, in their 20's, and in their 30 's. This activity took a great deal of time and was realized by the facilitators that in order to have time for the group members to write down what they learned in a letter to a future boy who may be in the group, visualization would not likely occur. Once they were asked to write the letter, resistance came from the first group. They stated not feeling comfortable writing to a boy whom they do not know. The group members were 
reminded by the facilitators that everything they said would remain anonymous. They voiced feeling much more comfortable writing a list or paragraph describing what they learned. Termination was less difficult than previous groups lead by this author, as the mutual feeling that individual contact between group members and the facilitators would continue was stressed by the facilitators. Also the group members were in two adjacent advisories together, so the contact would continue for them as two separate groups as well.

Posttest measures (from the experimental and control groups) were collected one week after termination of the intervention group (week 9).

\section{Research Design}

This quasi-experimental study occurred in the natural school setting and attempted to uncover the relationships between the implementation of a hardiness curriculum and the subsequent changes in measured levels of hardiness attitudes, self-esteem, and perceived total social support in urban adolescent males using a nonrandom assignment.

The research questions required the analysis of overall changes in pre- and posttest scores on the measures collected in the fall of 2005 . The preliminary analysis involved the examination of the pretest and posttest scores of the groups to determine the stability of test scores. This sample size varied depending on the analysis that was performed (listwise procedure). This will be explained in each of the analyses.

This research explored whether or not the dependent variables were significantly correlated in the pre- and posttest. The correlation between variables reflects the degree to which the variables are related or the degree of linear relationship between the variables. The degree of the relationship ranges from +1 to -1 . When interpreting the 
bivariate correlations, caution was taken as it is well established that correlation coefficients do not give an indication of the direction of causality. The correlation coefficient squared $\left(r^{2}\right)$ is reported and provides a measure of the amount of variability in one variable that can be explained by the other. Intially, three sets of bivariate correlations were performed. With the pretests, a bivariate correlation (Pearson Product Moment Correlation or Pearson $r$ for short) was performed on the entire sample that had pretest scores for all three dependent variables $(N=35)$. Bivariate correlations were then performed on the experiemental $(n=22)$ and control $(n=24)$ group subsamples.

Three $2 \times 2$ mixed design analyses of variances (ANOVA) were used to determine the differences in the means of the measures between the groups across the pre- and posttest time frame. A univariate approach was determined to be the best in looking at mean differences between groups on the three dependent variables: hardiness attitudes, self-esteem and perceived total social support. An ANOVA is able to show main effects or how the variables interact with each other and the possible interactions that may or may not exist (Keppel, 1991). An ANOVA is an omnibus test, which tests for an overall experimental effect. Only those participants who could be matched by a preand posttest were included in the ANOVA. The subsample size for the three ANOVA's ranged from 17 to 26 depending on which variable was analyzed. The alpha level was set at .01 . 


\section{CHAPTER IV}

RESULTS

Normality of the distribution of scores was tested using the Kolmogorov-Smirnov (K-S) test. Distributions for measures of hardiness attitudes, self-esteem and perceived total social support were normal, as indicated by the nonsignificant results of the K-S tests. Therefore, the assusmption of normality was not violated. See Table 1.

\section{Table 1}

Tests of Normality: Hardiness attitudes, Self-esteem and Total Social Support

\begin{tabular}{lllll}
\hline & & \multicolumn{3}{c}{ Kolmogorov-Smirnov } \\
& & Statistic & df & Significance \\
\hline \multirow{3}{*}{ Hardiness attitudes } & Experimental & .082 & 25 & .200 \\
& Control & .159 & 28 & .068 \\
\multirow{2}{*}{ Self-esteeem } & Experimental & .127 & 25 & .200 \\
& Control & .110 & 28 & .200 \\
\multirow{2}{*}{ Total Social Support } & Experimental & .113 & 25 & .200 \\
& Control & .105 & 28 & .200 \\
\hline
\end{tabular}

To assess the linear relationships between hardiness attitudes, self-esteem and perceived total social support, bivariate Pearson correlations were conducted on the overall sample's pretest scores and subsample posttest scores. In the pretest $(N=35)$, as shown in Table 2, hardiness attitudes and self-esteem were found to be significantly correlated in the pretest $(r(34)=.598, \mathrm{p}<.01)$. Self-esteem can account for approximately 
36 percent of the variability in hardiness attitudes $\left(r^{2}=.358\right)$. Self-esteem and perceived total social support were found to be significantly correlated in the pretest $(r(34)=.434$, $p<.01)$. Self-esteem can account for approximately 19 percent of the variability in perceived total social support $\left(r^{2}=.188\right)$. Finally, hardiness attitudes and perceived total social support were not found to be significantly correlated in the pretest $(r(34)=.287$, $p=.095)$.

Table 2

Intercorrelations Between Dependent Variables for Students (Pretest) Dependent Variables Hardiness Attitudes Self-Esteem Social Support

$\begin{array}{lccc}\text { Hardiness Attitudes } & ---- & .598^{*} & .287 \\ \text { Self-Esteem } & ---- & -\ldots-. & .434^{*}\end{array}$

*Correlation is significant at the 0.01 level (2-tailed).

Listwise $\mathbf{N}=35$

A listwise $(n=24)$ procedure was used to determine intercorrelations among the dependent variables for the posttest scores of the control group. As demonstrated in Table 3 , hardiness attitudes and self-esteem were found to be significantly correlated in the posttest $(r(23)=.703, p<.01)$. Self-esteem can account for approximately 49 percent of the variability in hardiness attitudes $\left(r^{2}=.494\right)$. Self-esteem and perceived total social support were found to be significantly correlated in the posttest $(r(23)=.603, p<.01)$. Therefore, perceived total social support can account for 36 percent of the variability in 
self-esteem $\left(r^{2}=.364\right)$. Hardiness attitudes and perceived total social support were not found to be correlated in the posttest $(r(23)=.328, p=.118)$.

\section{Table 3}

Intercorrelations Between Dependent Variables for Control Group (Posttest)

\begin{tabular}{lccc}
\hline Variables & Hardiness Attitudes & Self-Esteem & Social Support \\
\hline Hardiness Attitudes & ---- & $.703^{*}$ & .328 \\
Self-Esteem & ---- & --- & $.603^{*}$ \\
\hline
\end{tabular}

* Correlation is significant at the 0.01 level (2-tailed). Listwise $n=24$

A listwise $(n=22)$ procedure was used to determine intercorrelations among the dependent variables for the posttests of the experimental group. As demonstrated in Table 4, hardiness attitudes and self-esteem were found to be significantly correlated in the posttest $(r(21)=.719, p<.01)$. Self-esteem was found to account for approximately 52 percent of the variability in hardiness attitudes $\left(r^{2}=.517\right)$. Hardiness attitudes and perceived total social support were found to be significantly correlated in the posttest $(r(21)=.509, p<.05)$. Perceived total social support was found to account for 26 percent of the variability of hardiness attitude scores in the experimental group $\left(r^{2}=.259\right)$. Selfesteem and perceived total social support were not found to be correlated in the posttest $(r(21)=.151, p>.501)$. 
Table 4

Intercorrelations Between Dependent Variables for Experimental Group (Posttest)

\begin{tabular}{lccc}
\hline Variables & Hardiness Attitudes & Self-Esteem & Social Support \\
\hline Hardiness Attitudes & ---- & $.719 * *$ & $.509 *$ \\
Self-Esteem & ---- & ---- & .151 \\
\hline
\end{tabular}

* Correlation is significant at the 0.05 level (2-tailed).

** Correlation is significant at the 0.01 level (2-tailed)

Listwise $\mathrm{n}=22$

Table 5 provides the pre- and posttest means for the dependent variables hardiness attitudes (HA), self-esteem (SE) and perceived total social support (TSS).

Table 5

Pre- and Posttest Means

\begin{tabular}{ccc} 
& Pretest & Posttest \\
& Mean & Mean \\
\hline Experimental Group* & 33.091 & 33.182 \\
Hardiness Attitudes & 21.941 & 20.235 \\
Self-esteem & 235.619 & 237.524 \\
Total Social Support & & \\
Control Group** & & 33.346 \\
Hardiness Attitudes & 33.577 & 20.579 \\
Self-esteem & 22.053 & 254.692 \\
\hline
\end{tabular}

*Experimental Group Subsample Sizes: $\mathrm{HA}=22 ; \mathrm{SE}=17$; $\mathrm{TSS}=21$

**Control Group Subsample Sizes: $\mathrm{HA}=26 ; \mathrm{SE}=19 ; \mathrm{TSS}=26$ 
A mixed design ANOVA was conducted on the PVS-IIIR hardiness attitudes scores between the experimental group $(n=22)$ and the control group $(n=26)$, across the pretest and posttest measures, with alpha set at .01 . The main effect for treatment was not found to be statistically significant $F(1,46)=.039, p=.844$, nor was the main effect for the pretest-posttest comparison $F(1,46)=.011, p=.918$. The interaction between treatment and pre- and posttest was also not significant $F(1,46)=.056, \mathrm{p}=.813$. See Table 6.

Table 6

Analysis of Variance for Hardiness Attitudes

\begin{tabular}{lcccc}
\hline Source & df & $\begin{array}{c}\text { Sum of } \\
\text { Squares }\end{array}$ & $\begin{array}{c}\text { Mean } \\
\text { Square }\end{array}$ & F \\
\hline Treatment & 1 & 2.52 & 2.52 & .039 \\
Error & 46 & 2962.105 & 64.394 & \\
Time & 1 & .117 & .117 & .011 \\
Treatment x Time & 1 & .617 & .617 & .056 \\
Error & 46 & 503.217 & 10.939 & \\
\hline
\end{tabular}

A mixed design ANOVA was also conducted on the Rosenberg (1967) selfesteem scores between the experimental group $(n=17)$ and the control group $(n=19)$, across the pretest and posttest measures with alpha set at .01 . No statistically significant main effects or interaction effect were found. See Table 7. 
Table 7

Analysis of Variance for Self Esteem

\begin{tabular}{lcccc}
\hline Source & df & $\begin{array}{c}\text { Sum of } \\
\text { Squares }\end{array}$ & $\begin{array}{c}\text { Mean } \\
\text { Square }\end{array}$ & F \\
\hline Treatment & 1 & .929 & .929 & .014 \\
Error & 34 & 2263.446 & 66.572 & \\
Time & 1 & 45.353 & 45.353 & 3.953 \\
Treatment x Time & 1 & .242 & .242 & .021 \\
Error & 34 & 390.133 & 11.475 & \\
\hline
\end{tabular}

A mixed design ANOVA was conducted on the CASSS (Malecki et al., 2000) perceived total social support scores between the experimental group $(n=21)$ and the control group $(n=26)$, across the pretest and posttest measures with alpha set at .01 . The main effect for treatment was not found to be statistically significant $F(1,45)=1.274, p$ $=.265$. A statistically significant difference was not found for the pre- and posttest comparison $F(1,45)=.105, p=.748$. The interaction between treatment group and preand posttest was not significant $F(1,45)=.002, \mathrm{p}=.965$. See Table 8 . 
Table 8

Analysis of Variance for Total Social Support

\begin{tabular}{lcccc}
\hline Source & df & $\begin{array}{l}\text { Sum of } \\
\text { Squares }\end{array}$ & $\begin{array}{c}\text { Mean } \\
\text { Square }\end{array}$ & F \\
\hline Treatment & 1 & 6613.026 & 6613.026 & 1.274 \\
Error & 45 & 233596.613 & 5191.036 & \\
Time & 1 & 112.696 & 112.696 & .105 \\
Treatment x Time & 1 & 2.058 & 2.058 & .002 \\
Error & 45 & 48407.155 & 1075.715 & \\
\hline
\end{tabular}

Response to Open-Ended Question

Participants were asked about what they learned from participating in the group.

Responses were scored using a rubric that provided a point each for listing the following: hardiness, commitment, control or challenge. One point was given for each thing listed as something the participant learned. Overall, 21 participants responded, with a mean of 3.9. Table 9 shows a summary of the reported responses. 
I learned how to as(Group) make us feel better about ourselves

I learned how to problem solve

I learned how to use coaches

I learned how to use social supports

Getting together to (learn) to control our behaviors; how to control myself

How to deal with problems

How to ask people that are close to us to help

Finally have someone to talk to about my problems

Put commitment into all my problems; don't stop until my problems are solved

I learned how to control my temper

Ask someone for help

The group helped me get more control in my life

I learned how to overcome challenges

I learned how to meet new people

I learned about obstacles we have

I learned everyone has their own story, no matter how strange or crazy it may sound I learned about making decisions

I learned that no matter how bad your life is, you can still have a positive attitude The group was about expressing our feelings and talking about every day problems The group taught me to not be afraid to say what is on my mind I learned how to resolve a problem in a more positive manner I learned how to overcome many more obstacles

I learned how to have much more self-confidence and self-esteem

This group was about controlling your attitude

Being committed to something you like to do or your passion

Challenge yourself to the best 


\section{CHAPTER V \\ DISCUSSION}

To adapt positively in the face of adversity is the definition of resilience (Luthar, Cicchetti, \& Becher, 2000), which has been shown to protect individuals psychologically (Garmezy, 1991). The personality trait of hardiness is one possible pathway to resilience (Bonanno, 2004) that may potentially buffer stress in adolescents. The development of a hardiness approach to enhancing performance and health began in 1974 (Maddi, 2002). Findings from Kobasa's (1979) dissertation state that individuals who showed certain attitudes when stressed experience fewer mental and physical illness symptoms. These attitudes became known as "stress buffers" and became conceptualized as the three hardiness components: commitment, control and challenge (Maddi, 2002). The concept of enhancing these components to help others alleviate the symptoms of stress developed into a hardiness approach. This approach continues to be developed through the hardiness theory. Relevant research has been applied and aided in the creation of Hardiness Training designed for adults only at this time, although Dr. Maddi has stated that, "In our tumultous times...it is essential that hardiness also be applied in primary prevention...it would be even better to expose elementary and high school students to hardiness assessment and training..." (Maddi, 2002, p. 182).

This exploratory quasi-experimental study sought to answer the basic question regarding the implementation of a hardiness curriculum with adolescents: do urban adolescent males who attend an 8-week hardiness training experience significant changes on measures of hardiness attitudes, self-esteem and perceived total social support when compared to a control group? The intervention was designed by three clinical social 
workers to specifically teach both didactically and experientially the concept of hardiness and its three components.

\section{Correlations}

High correlations between self-esteem and hardiness have been cited (Bernard, Hutchinson, Lavin, \& Pennington, 1996). There is also a well-established relationship between self-esteem and psychological well-being, therefore gaining higher levels of self-esteem can serve as a protective factor in male adolescents (Blascovich \& Tomaka, 1991; Robins et al., 2002). The findings for this study are consistent with other findings of a relationship with hardiness attitudes and self-esteem. Results showed that measured levels of hardiness attitudes and self-esteem were significantly correlated in the pretest measures and posttest measures for the overall combined group sample as well as the subsamples (i.e., the control and experimental groups). Self-esteem was found to account for approximately 36 percent of the variability in the hardiness attitudes in the pretest for the overall sample. Self-esteem accounted for approximately 49 percent and 52 percent of the variability in hardiness attitudes in the posttest for the control and experimental groups, respectively. Perceived total social support was found to account for 26 percent of the variability of hardiness attitude scores in the posttest of the experimental group only.

Perceived total social support significantly correlated with self-esteem in the overall pretest sample. Perceived total social support was found to account for approximately 19 percent of the variability in self-esteem in the pretest. For the control group posttest scores, perceived total social support was found to account for 36 percent 
of the variability in self-esteem. There was not a significant relationship found between perceived total social support and self-esteem in the experimental group.

\section{Hardiness Attitudes}

Findings from the analysis of variance indicates that overall, there were neither main effects of treatment and time nor interaction effects found to be statistically significant. These finding suggests that the intervention, as offered, did not cause changes in the measured levels of hardiness attitudes. As this was not a longitudinal study, long-term effects were not considered nor could they be measured. It is therefore, unclear of what long-term effects would be found.

The curriculum was designed to be offered one time per week. One study that evaluated the effectiveness of hardiness training using a population of high-risk undergraduate Caucasian students in their first semester of college (Maddi et al., 2002) found that the participants in the experimental group had higher scores on measures of hardiness attitudes after the course was offered and higher grade point averages after one year than the control group. Overall, implications of Maddi et al.'s study (2002) suggest that hardiness training has a positive influence on hardiness attitudes with a population of Caucasian students when offered two times per week for an entire college semester (Maddi et al., 2002). The length of the intervention, the age and ethnicity of the students, as well as the long-term measured effects are variables, which differed from the present study and may have influenced the results.

Another possible factor in the insignificant finding is whether the PVSIII-R adequately reflects hardiness for this selected population of male adolescents. Although the measure has been used with adolescents, its validity and reliability as an instrument 
for younger adolescents beginning at age 13 has not been sufficiently studied. Several questions in the instrument ask about "work" and although the participants were asked to substitute "work" with the words "school work" they may not have fully understood the questions. The construct or concept of hardiness may also be difficult for adolescents to grasp and could very well be too abstract for the population. In the future, using other instruments designed to measure hardiness attitudes in adolescents may be more effective.

Anecdotal and informal observations suggest that long-term effects may be of importance. For example, when the participants were asked about what they learned from participating in the group (see Table 9), one hundred percent of the participants $(n=21)$ who answered the question were able to state three or more terms from the group (i.e., list hardiness and its components) and/or something they learned. Examples included: they learned how to control behaviors; ask people to help them with problems; how to overcome challenges. Although these responses possibly indicate change, a measure of observed behaviors (either by teacher or parent) was not included. There is no way to see if these participants were providing the socially desirable responses or whether their behaviors actually changed.

In three informal interviews with three different participants, vocabulary included the terms "control," "challenges" and "obstacles." This is relevant in that it appears participation in the group has provided these young men with new vocabulary they can use to express themselves. It is likely that the measures selected by this researcher did not capture the changes experienced by the experimental group's participants. Future groups 
offered at the Met may include advisors within the structure of the group. This would enable the advisors to learn and later reinforce the concepts learned in the group.

Self-esteem

Findings from the analysis of variance indicates that overall, there were no statistically significant changes in measured levels of self-esteem one week following completion of the hardiness curriculum. Particpants' self-esteem scores may have failed to increase one week post intervention for many reasons. Although the intervention was, in fact, aimed at helping the participants see themselves in a more positive light, previous studies have shown that a self-esteem may be less amenable to change with a brief intervention due to the complexity of the concept and the enduring characteristics of individuals (Bitonti, 1992). Self-esteem, however, has been shown to be altered if there are significant changes in the areas that the adolescent judges to be of importance and if there is the existing approval from the adolescent's significant others (Harter, 1993). Harter's (1993) research found that using an intervention with adolescents undergoing an educational transition may have a greater significant impact on the adolescents attending the group intervention.

Furthermore, because this intervention was geared towards enhancing hardiness directly and indirectly towards enhancing self-esteem, Shirk, Burwell and Harter (2003) suggest that treatments focused on a specific target tend to produce, “...more beneficial effects than treatments that attempt to affect an associated target indirectly..." (p. 191). Although changes in self-esteem can be seen in adolescents who work on practicing problem solving skills and improving relationships, additional benefits are found in treatment strategies that directly target self-esteem (Shirk et al., 2003). It is therefore 
likley that because the hardiness curriculum did not directly target self-esteem, the curriculum was not effective in increasing participant self-esteem significantly. Perceived Total Social Support

Results indicate that there were no statistically significant changes in measured levels of perceived total social support one week following completion of the hardiness curriculum. A possible explanation is that the instrument chosen (CASSS) was not designed specifically for an urban adolescent population. It was also lengthy (60 items) and was presented last after the other scales were completed. General boredom may have lead the participants to a rapid and insincere completion of the scale.

In a similar unpublished study conducted simultaneously using ninth grade girls $(n=71)$ from the Met School, Butke (2006) hypothesized that the nature of the group intervention, being highly experiential, would cause participants to demonstrate an enhanced ability to cope in healthier and more positive ways. She chose to measure this effect using the Adolescent Coping Orientation for Problem Experiences, or the A-COPE (Patterson \& McCubbin, 1983). This instrument assesses an adolescent's coping mechanisms and then categorizes them into 12 different categories. Four of the coping mechanisms are directed at avoidance of issues, while the remaining eight coping patterns seem to be in the realm of transformational coping (Patterson \& McCubbin, 1983). The main effect of the intervention with females appeared to be their ability to change their behavior and increase their repertoire of positive coping resources. The findings of Butke's (2006) study suggest that coping abilities can be enhanced in urban adolescent females who are experiencing a change in school environment. She did not have significant findings with the PVS-IIIR or the Rosenberg Self-esteem Scale. She did 
not choose to use the CASSS with her groups. Because the CASSS as well as the other two measures used in this present study were all self-report instruments, participant reliability is a concern. Participants may have been likely to misperceive the instruments or censor themselves when completing them. Another issue of concern is whether selfreport surveys actually relate to real behavior in adolescents. The CASSS is designed to capture and measure perceptions of social support, while the A-COPE addresses behavior. The A-COPE may be the only measure presented to the participants which was designed to actually target changes in behavior. It remains unknown whether Butke's (2006) results are replicable with females attending traditional public schools.

\section{Limitations of the Research}

Limitations of this study include the use of cross-sectional data. The approach adopted was exploratory, given the absence of previous empirical evidence on hardiness attitudes, self-esteem and perceived total social support in an urban adolescent male population. This sample of subjects was limited to males attending an alternative school setting, therefore it remains unknown how the hardiness curriculum may or may not work in a general school setting with males and/or females. The groups that the males attended were also involuntary. A smaller group of voluntary participants may produce different results.

The 51 participants of the study were tested within a 9-week period using the same measures each time and the experimental group was exposed to a treatment that hoped to enhance many of the qualities or characteristics that were emphasized in the actual scales. 
The anonymous code that the participants created presented itself as a barrier. Many of the pretests completed by the participants could not be matched to the posttests. Therefore, testing, the effects of retaking the same test and recreating an anonymous code affected the internal validity of this study. Attendance was also a limitation of the study. Some of the participants had weak attendance, while others were enrolled at the Met midway through the group, therefore preventing a pretest measure to be collected and matched in the specified time frame.

Another limitation was the diffusion of the treatment. Various students from the experimental group encountered members of the control group in after-school extended day programs. There were also random irrelevancies in the experimental setting. The groups were located at different campuses, thus they had a different feel and influence on the students. The external validity of this study was therefore affected by the interaction of each setting and the treatment. The setting is also unique and presented various interactions with the intervention. The major disadvantage to using only ninth grade urban adolescent males in the study is that the results are not generalizable to the general population, but rather to adolescent males attending an alternative school.

Construct validity was influenced by this researcher's mono-operation and monomethod bias, as participants recorded their responses via scales and one open-ended question. The participants may have engaged in hypothesis guessing within experimental conditions (i.e., Hawthorne Effect) and answered the open-ended question with a socially desirable response.

A final limitation addresses the fact that data collection over very short periods of time only provides a brief snapshot of the interrelationships of hardiness, self-esteem, and 
perceived total social support, whereas longitudinal data allows for the examination of both within and across discrete time periods. Given the brief time period, it makes it difficult to interpret the true long-term effects of the hardiness curriculum on a sample of urban male youth.

Implications for Research

The long-range goal for this study is to continue developing and researching an intervention that will help urban adolescent males learn how to face adversity in a positive and flexible manner. Perceptions about the self are more difficult to change than first imagined. Additionally, through this project it became apparent that specific interventions designed to directly target self-esteem may prove to be more beneficial to the students.

Directions for Future Research

Because the results of the study were not promising, additional research is warranted. The use of self-report instruments was used for this project. This may or may not relate to real behaviors. The larger question is whether or not perceptions need to change in order for the behaviors to change. Qualitative data from parents/caregivers and Met staff may have added strength to the study by providing outside perspective on the observable changes in participant behavior.

Longitudinally, a study that measures the long-term effects of a hardiness curriculum would aid psychologists in understanding how the curriculum effects its participants after completion of the group. Including advisors within the structure of the group intervention or as a co-facilitator will allow for reinforcement of the key concepts following the completion of the intervention. 
Offering the hardiness curriculum for a longer period with a smaller number of voluntary participants may influence results. The concept may be too difficult to grasp in only 8 weeks. The concept may be better understood by 11 th and 12 th grade students.

\section{Conclusion}

At the initiation of this project, there were no other known interventions in the literature specifically designed to enhance hardiness in urban adolescent males. The gender-specific design was also unique in addressing the variables of self-esteem and perceived total social support. Results of this study provide some insight into an initial attempt to enhance hardiness through an intervention. The suggestions offered hope to educate others in the future on how to enhance and improve a hardiness curriculum. This study is an important first step in making any other future attempt in this worthwhile direction. 
Appendix A

IRB Approval Sheet

DATE: $\quad 10 / 26 / 05$

Review Assigned: Exempt

Exempt Category:

4) Existing Data, Tissue, etc. if publicly available or anonymous

TO: Dan Koonce

Lea Lockwood

FROM: Diana V. Brown, Director of Compliance

RE: $\quad$ "Enhancing Hardiness in Urban Adolescent Males: A Hardiness Curriculum"

Your Proposal was reviewed by the Office of Compliance in the Research Office. and it was determined that the use of human subjects in this project falls into the "exempt review" category. In the case of "exempt" research, IRB approval is valid for the duration of the project. It is the responsibility of the research investigator to acknowledge and accept responsibility for protecting the rights and welfare of human research subjects and for complying with all applicable federal and institutional regulations.

Under applicable regulations, no changes to procedures involving human subjects may be made without prior review and approval. The regulations also require that you promptly notify the Office of Compliance of any problems involving human subjects that arise during the course of your work.

Enclosed is the IRB Action Report certifying approval of your project. If your proposal included an Informed Consent document, it has been stamped "approved" by the IRB and returned. Please use this stamped consent form for your research, remembering that the subject keeps one signed consent document, and you keep one signed consent document for your records.

If you have any question about the IRB process, or if you need assistance at any time, please feel free to contact me at the Research Office at (401)874-4328.

Your Thesis/Dissertation Proposal Approval Sheet has been signed and is here at the Research Office for you to pick up and bring to the Graduate School. 
Appendix B

Hardiness Group Manual

\section{Overview of Intervention}

The intervention is specifically designed to provide education about hardiness and to provide participants with specific tools and skills and experiences which cultivate the qualities of hardiness. Each of the 8-week sessions is structured with a specific focus and a task that addresses an aspect of hardiness, specifically the qualities of control, commitment and challenge. The groups are designed so that one week, the key concept is introduced and the following week, the participants will practice using the skills they have learned.

The participants are encouraged to discuss past experiences specifically as they relate to high hardy and low hardy experiences. Each session will begin and end with a check-in related to the concept of hardiness and experiences from the previous week. Participants will also use a journal, distributed at the first group, to record their experiences with hardiness. 


\section{Session\#1: Introduction to Group and Hardiness Concepts}

Overview: The first session will focus initially on group guidelines, norms and the development of connection among the participants. Specifically, the guidelines around confidentiality will be reviewed and agreement among members to keep group experiences confidential will be sought. Attendance will be taken. The overall framework for the 8-week group will be explained. The concept of hardiness will be introduced: Hardiness is something we all have within our personalities at varying degrees. It is made up of control, commitment and challenge. Hardiness is a personality characteristic that can be enhanced or improved through experiences (like this group). Being high in hardiness will help one manage stress and problems in a healthier manner. Overall, the way you look at situations in your life will determine how you cope with them. Example: Show a glass of water. Ask the group is it half full or half empty.

\section{Objectives:}

1. Establish group norms and guidelines

2. Introduce and explain hardiness concepts

3. Relationship building

Check In: Participants will be asked to go around and state one thing they want from this group.

Educational Component: The words "Control", "Commitment" and "Challenge" will be written on poster board with definitions (as described below).

Control: The belief that you can control some events in your life. 
- Example 1: What are some of things in your life that are controlled by your caregiver? What are other situations or activities that you make all the decisions about?

- Example 2: If you would like to get an internship, what should you be doing right now to ensure get a successful placement? What internships would you like to pursue? Who controls whether or not you are accepted? Can you do anything to influence that decision?

Commitment: Refers to your ability to connect with and utilize social supports, friends and family.

- Example: What groups of adolescents do you share your time with during the week? Who do you choose to spend time with on the weekend? Do you belong to organizations or sports teams? What are you passionate about?

Challenge: Viewing change as a challenge (rather than a threat). This concept involves being flexible when things start to change in your life and describes individual's perception regarding the change. (What "story" does the person create about this occurrence?)

- Example 1: Remember back to the beginning of this year. How different did it feel to now be at the Met? Were there good changes happening? What about the "not so good" changes? What were those?

- Example 2: What challenges might you face after you graduate from the Met? What might feel uncomfortable about those changes? Overall thought questions for group:

- What does it mean (in your own words) to be hardy? 
- Participants will be encouraged to discuss past experiences with hardiness. Experiential Activity: Participants will be asked to participate in a role-play. The roleplay will emphasize control, commitment and challenge in a scene between students. The goal of the role-play is to highlight how misperceptions and individual roles can positively and negatively influence situations. Every participant will be assigned a role, either as a player or observer in the role-play.

\section{Summary and Application Question:}

The participants are given journals and requested to write down their answer to the question: How do you want to be in the world?

\section{Session 1: Role Play}

Scenario: Jon is a ninth grade student who is generally well liked by students. He is usually on-task during independent work time. He has an LTI at a photo shop and really enjoys the work. Last week the cash register was short by fifty dollars and all of the people who were working there were under suspicion. They caught the thief using the security camera. Jon works in the retail section while a tenth grader, Sammy, works in processing. Only the retail staff was suspected because they had access to the register. Jon's advisor and principal knew about the incident, but Jon didn't want other people to know. A few of his close friends knew he was on probation a few years ago for shoplifting. 
Sammy was not so psyched about Jon having his LTI at the same place (turf issue).

Sammy really wants to work there during the summer. When Sammy heard about the robbery, he started saying things about Jon. Sammy also heard that Jon had a prior history of shoplifting. Jon kept a low profile until he was cleared, but is now confronting Sammy about the lies Sammy said about Jon.

Scene escalates into a physical confrontation and staff break it up.

Roles for students:

1. Jon's friends

2. Sammy's friends

3. Jon

4. Sammy

5. Principal

6. Advisor 


\section{Session \#2: Cultivating Commitment}

Overview: The participants who are willing, will be asked to share their journal entry from last week (How do you see yourself in the world?). Concept of commitment will be introduced: Wanting to stay involved with other people and events. Session will address how group, school, and their community can nurture commitment. Being strongly committed may include seeing withdrawal into isolation as a waste of time.

\section{Objective:}

1. Enhance participants' understanding of commitment

2. Help participants explore whom they are committed to and who is committed to them.

Check In: Participants will check in about the first group and about the question of how they want to $b e$ in the world.

Educational Component: Commitment: wanting to stay involved with people and events; may see withdrawal into isolation as a waste of time. Commitment includes seeking out social supports and asking for help, when needed. It also involves making a commitment to oneself.

Experiential Activity: Participants will be given paper and markers/pens. The question will be asked: Whom do you use as your social support? They will be asked to make a list of the social supports in their lives (past and present). The following prompts will be listed on poster board:

- Teachers

- Coaches

- Grandparents 
- Parents

- Surrogate mothers/fathers

- Other caregivers

- Principal

- Counselors/Social Workers

- Your Advisor/Other Advisors

- Foster Parents

- Church Members

- LTI mentors

1. One participant will be asked to volunteer to create a social support sculpture. This participant will then be asked to pick nine of these people and write their names on cards and pass the cards out to other group members. This participant will be asked to place these "actors" in positions of where you see them in your life (i.e., near your person, always at your back, across the room).

2. Next, the social support "actors" will be asked to turn their backs to the participant. The following situation will be read aloud to the participant: You are getting ready for your exhibition. Who are the first people/persons you use? These people would then face the person one at a time. The group will be prompted for other "real life" situations. The question would then be asked: Who do you want to turn to first? Second? 
3. All participants will be asked to then depict their social supports on paper using markers (or play dough).

\section{Summary and Application Question:}

Answer the question in your journal: how do you show gratitude? Find someone new in the building (maintenance person, security guard) and introduce yourself. Make sure to get their name! 


\section{Session \#3: Commitment, continued}

Overview: Commitment will be continued this week. The session will continue to focus on the experiential aspect of commitment and how one demonstrates commitment to oneself. Participants will process group experiences and discuss how the group is going. There will be discussion on keeping promises and participants will explore what gets in the way of their commitments.

\section{Objectives:}

1. Review previous week's discussion.

2. Facilitate a discussion about creating an effective support system for different situations

3. Foster development of commitment to oneself

Educational Component: Participants will continue with the work of the previous week, and will have exercises designed to anchor the experience of commitment. Educational component will focus on the ways one can commit to oneself. The group will explore the idea of being aware when one makes commitments/agreements and what happens when we break our agreements with one another and oneself.

Experiential Activity: Participants will work with the idea of commitment to self by doing "I promise statements". The group will be shown a list of possible promises and obstacles. 


\section{PROMISES:}

I promise myself to graduate from high school.

I promise myself to go to college.

I promise myself that if I decide to have children, it will be a planned pregnancy.

I promise myself that if I choose to be sexually active, I will be safe.

I promise myself to seek out help when I am feeling overwhelmed about

\section{OBSTACLES:}

Cannot wake up on time.

Cannot pass into the next grade because I have not been at enough LTI's.

I have to baby-sit my siblings.

I do not get along with my advisor or advisory.

Participants will brainstorm a list of potential promises and obstacles that may effect the fulfillment of their promises. The group will brainstorm together, and then they will pair up with a peer to work on their list. They will be asked to first find a person with whom they would be most likely to work. Next, they will be asked to switch partners and find someone with whom they less frequently work. This second person will be their work partner. One person in the pair will be asked to write down at least five possible obstacles to a promise they want to make. The written out obstacles will be passed out to other participants. The participants will be spread throughout the room like a human obstacle course. The object is for the participant to face each obstacle and pass through to the next one by verbalizing how they overcame the obstacle. Their partner will 
become the participant's "coach". The coach will offer assistance and support as the participant moves through the obstacle course.

\section{Summary and Application Question:}

What is one promise you can make to yourself this week? 


\section{Session \#4: Cultivating Control}

Overview: Control will be fostered in the next two group sessions. Participants will be asked to discuss situations in which they felt powerless to control the outcome in their life situations.

\section{Objectives:}

1. Students will review the promise activity and prompted to talk about a promise that they kept this past week.

2. Students will understand the quality of control and will assess ways they can enhance their feelings of self-efficacy.

3. Students will explore the different ways they feel a sense of control in her life and will look at times when they powerless.

Educational Component: Participants will talk about times they have felt powerless to effect change or have a say in their lives. They will also explore alternatives to those situations which would enable them to feel a greater sense of control. Control will be discussed in contrast to powerlessness - the feeling that life just happens to people, and you cannot really do anything about it.

Experiential Activity: The group members will brainstorm areas in their lives when they feel out of control, or powerless. They will confidentially put these examples into a container, with group leaders also adding several scenarios to the group (i.e., teen pregnancy, condom usage, substance abuse, physical abuse). The group will then vote on the scenario to be role-played and assigned roles to act out. Follow-up questions for group: 
- If you were the boy in this scenario, what might you have control over?

- If you were the boy in this scenario, what wouldn't you have control over?

- What are some strategies for dealing with this situation?

Summary and Application Question: Write about an area in your life where you feel you have no control. Then, using the technique from this week's group, write about the ways you may exercise some control in the area you chose. 


\section{Session \#5: Cultivating Control, continued}

Overview: This session will continue to focus on the area of establishing a sense of selfefficacy. The participants will continue to explore the ways they can establish a sense of control in their lives.

\section{Objectives:}

1. Participants will deepen their understanding of the area of hardiness-control.

2. Participants will experience a situation where they will practice in the area of control.

3. Participants will discuss ways of coping when they feel that situations are out of their control.

Check In: Participants will check in about group and last week's questions regarding control.

Educational Component: Co-leaders will discuss different coping styles including the following:

- Avoidant Coping - trying to stay away from dealing with difficult situations (i.e., drinking, drugs, watching TV, reading).

- Social Support Coping - going to others to get help in difficult situations.

- Humor- Joking or making light of situations.

- Expressing Feelings

- Dealing with Situations Directly and using optimism to Cope

- Seeking out Religious Solutions

- Engaging in a Demanding Activity 
Experiential Activity: Participants will role-play difficult situations and will each play out differing coping strategies to demonstrate them.

Summary and Application Question: Name the three most common coping strategies you use during stressful situations.

\section{Boy's Group Session \#5 Role Play}

1. John is a ninth grader at the Met School. He lives in Providence, in a dangerous part of town. He has older brothers and sisters who watch out for him, but he never asks them for help. His LTI this year is in Johnston and the bus that brings him home drops him off 10 blocks from his house. Being December, it gets dark at 4:30 PM. His bus drops him off at 5 PM. He knows he has to pass by drug dealers, prostitutes and gang members. He loves his LTI, but is scared to walk home at night. He regularly hears gunshots in the streets as he walks home. Today he is going to speak with his advisor, Sammy, about changing LTI's. He is afraid to tell Sammy the truth as to why he wants to quit.

Use the following coping styles: avoidant coping and humor

2. Your mom (Lidia) has been dating her fiancé (Mark) for 13 months. You like Mark he was a star football player at Central and always gives you things you want. However, you noticed that as soon as he moved into your apartment, he got laid off from work. Mark has been drinking with his buddies at night since he lost his job. Last night, Mark came home drunk and slapped your mom across her face because she didn't have dinner waiting for him. 
Use the following coping styles: social support coping and dealing with the situation directly and using optimism to cope

3. You have been dating the same girl, Tisha, for the past four months. Your girlfriend is on birth control, but forgot to take the pill two days last month. She didn't get her period this month and took a pregnancy test. It was positive.

Use the following coping styles: engaging in a demanding activity and avoidant coping 


\section{Session \#6 Nurturing challenge}

Overview: The focus of this session will be on introducing the concept of hardinesschallenge. The idea will be introduced through the utilization of a guest speaker. Participants will explore what challenge means in their own lives.

\section{Objectives:}

1. Participants will understand the concept of challenge and relate it to their own lives.

2. Participants will be exposed to areas of challenge that exist/existed in the lives of a guest speaker.

Check In: Follow-up on the role-plays and coping strategies demonstrated from previous session.

Educational Component: Challenge can be understood as a positive opportunity for growth, rather than a threat or through a negative lens. Challenge involves the idea of staying flexible and going in the direction of change, as opposed to resisting or fighting against it. It is essential to try to get across the idea that participants can shift the way they think about things. Once can use the perspective of a camera lens, or glasses with multiple color lenses. They can change their thinking through their intention. Explain the difference between positive thinking and positive focus.

- Positive thinking: "I am happy about the change in my life." This may not feel true to you, so you may feel like you are lying to yourself. 
- Positive focus: "Even though this change is hard for me, I want to be happy with the changes in my life." This sets your intention in a positive way, while also acknowledging the truth in the present.

Experiential Activity: Participants will listen to a guest speaker. The guest speaker will be brought in specifically for his/her own experience(s) with challenge and the manner in which they used a positive focus to transition through these experience(s).

Summary and Application Question: Write about a situation in your own life involving change. Write about how you would like to view this situation, given the work of challenge. 


\section{Session \#7 Nurturing challenge, continued}

Overview: Participants will address current situations involving transition and change. Working in pairs, they will come up with hardy skills/attitudes to address current situations.

\section{Objectives:}

1. Participants will understand the concept of challenge, and will learn how to see change through a more positive lens.

2. Participants will learn to "coach" one another around shifting lenses.

Check In: Participants will check in around the issue of challenge from the previous week.

Educational Component: Co-leaders will discuss the area of challenge and respond to questions from the group. The idea of supporting or "coaching" one another to deal with difficult situations will be discussed.

Experiential Activity: The participants will work in pairs to address a current situation where they feel powerless to effect change, and they will brainstorm with their partner ways to have a voice in the outcome of the situation. They will be given strategies for "coaching" their partner through the situation presented. Participants will then come back into the large group and share about their experiences.

\section{Summary and Application Questions:}

What questions do you have about hardiness - control, commitment, and challenge - or about coping strategies? What three ideas will you take away from this group? 


\section{Session \#8 Closing Group}

Overview: Review and reinforce key hardiness and coping concepts. The group will also practice future imaging where they imagine themselves at some time in the future, fulfilling their goals and dreams. Termination will also be a focus of the group.

\section{Objectives:}

1. To allow students to practice future scenarios of success using the hardiness and coping concepts

2. To terminate with the group and to process what they have learned from the group.

Check In: Participants will check in about this being the last group, and about what they want to take away from the group.

Educational Component: The participants will create a future scenario in their lives. Using the technique of visualizing the future in the present moment, they will imagine the future challenge and will envision themselves utilizing the tools and skills learned in the group. Participants will be encouraged to continue to seek out their supports from the group to assist them in remembering what they had learned.

Experiential Activity: Timeline to the future: The Participants will be guided through an exercise where they first write down significant experiences from their lives including early childhood (2-3 years old), childhood (5 - starting school), middle childhood (8-9 years old), pre-teen (11-12 years old), and current (14-16 years old). They will then be guided to write down experiences that they hope to have in the future - imagining themselves at high school graduation, in college, in their 20's, and in their 30's. They 
will be asked to write down these experiences. They will then stand, in a line, and with eyes closed, will be guided through a process of a moving timeline. Their future experiences will be anchored by used of this guided imagery.

\section{Summary and Application Question:}

How will you bring this group back into the rest of your school year?

\section{Final Assessment}

Write what you think is the purpose of the group and what you learned from participating in the group. 


\section{Appendix C}

\section{Personal Views Survey - III Revised}

Please answer the following questions to the best of you ability, and as honestly as possible. This is important for report accuracy. There are no right or wrong answers. Please answer each question by circling the number that best describes your current views or life situation.

\begin{tabular}{cccc} 
Not true at all & A little true & True & Very true \\
0 & 1 & 2 & 3 \\
\hline
\end{tabular}

1. By working hard, you can always achieve your goal.

2. I don't like to make changes in my everyday schedule.

3. I really look forward to My work.

4. I am not equipped to handle the unexpected problems in life.

5. Most of what happens in life is just meant to be.

6. When I make plans, I'm certain I can make them work.

7. No matter how hard I try, my efforts usually accomplish little.

8. I like a lot of variety in my work.

9. Most of the time, people listen carefully to what I have to say.

10. Thinking of yourself as a free person just leads to frustration.

11. Trying your best at what you do usually pays off

in the end.

12. My mistakes are usually very

difficult to correct.

13. It bothers me when my daily routine gets interrupted. 


\begin{tabular}{cccc}
$\begin{array}{c}\text { Not true at all } \\
0\end{array}$ & $\begin{array}{c}\text { A little true } \\
1\end{array}$ & $\begin{array}{c}\text { True } \\
2\end{array}$ & $\begin{array}{r}\text { Very true } \\
3\end{array}$ \\
\hline 0 & 1 & 2 & 3 \\
0 & 1 & 2 & 3 \\
0 & 1 & 2 & 3 \\
0 & 1 & 2 & 3
\end{tabular}

17. Most days, life is really

interesting and exciting for me

14. I often wake up eager to take up life wherever it left off.

15. Lots of times, I really don't know my own mind.

16. Changes in routine provokes me to learn.

3


Appendix D

Rosenberg Self-Esteem Scale

INSTRUCTIONS: BELOW IS A LIST OF STATEMENTS DEALING WITH

YOUR GENERAL FEELINGS ABOUT YOURSELF. IF YOU STRONGLY

AGREE, CIRCLE SA. IF YOU AGREE WITH THE STATEMENT, CIRCLE A.

IF YOU DISAGREE, CIRCLE D. IF YOU STRONGLY DISAGREE, CIRCLE SD.

$\begin{array}{lrrr}\begin{array}{l}\text { Strongly } \\ \text { Agree }\end{array} & \text { Agree } & \text { Disagree } & \begin{array}{c}\text { Strongly } \\ \text { Disagree }\end{array} \\ \text { SA } & \text { A } & \text { D } & \text { SD }\end{array}$

1. On the whole, I am satisfied

SA

A

SD with myself.

2. At times I think I am no good at all. SA

A D SD

3. I feel that I have a number of

SA

A

D

$\mathrm{SD}$ good qualities.

4. I am able to do things as well as most SA

A D $\quad$ SD
people.

5. I feel I do not have much to be proud of. SA

A D $\quad$ SD

6. I certainly feel useless at times.

SA

A

D

SD

7. I feel that I'm a person of worth,

SA

A

D

SD at least on an equal plane with others.

8. I wish I could have more respect for myself.

SA

A

D

SD

9. All in all, I am inclined to feel that I am SA

A

D

SD a failure.

10. I take a positive attitude toward

SA

A

D

SD myself. 
Appendix E

Child and Adolescent Social Support Scale

YOU WILL NOW BE ASKED TO RESPOND TO SENTENCES ABOUT SOME FORM OF SUPPORT OR HELP

THAT YOU MIGHT GET FROM EITHER A PARENT, TEACHER OR FRIEND. READ EACH SENTENCE

CAREFULLY AND RESPOND TO THEM HONESTLY. THERE ARE NO RIGHT OR WRONG ANSWERS.

FOR EACH SENTENCE YOU ARE ASKED TO PROVIDE TWO RESPONSES. FIRST, RATE HOW OFTEN YOU RECEIVE THE SUPPORT DESCRIBED AND THEN RATE HOW IMPORTANT THE SUPPORT IS TO YOU.

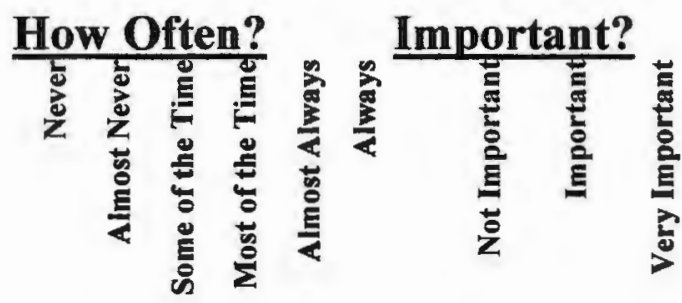

\section{MY PARENT(S)...}

1....show they are proud of me.

2.....understand me.

3....listen to me when I need to talk.

4....make suggestions when I don't know what to do.

5...give me good advice.

6 ...help me solve problems by giving me information.

7...tell me I did a good job when I do something well.

8 ....nicely tell me when I make mistakes.

9....reward me when I've done something well.

10 ...help me practice my activities.

11 ....take time to help me decide things.

12 ....get me many of the things I need

$\begin{array}{lllllllll}\mathbf{1} & \mathbf{2} & \mathbf{3} & \mathbf{4} & \mathbf{5} & \mathbf{6} & \mathbf{1} & \mathbf{2} & \mathbf{3} \\ \mathbf{1} & \mathbf{2} & \mathbf{3} & \mathbf{4} & \mathbf{5} & \mathbf{6} & \mathbf{1} & \mathbf{2} & \mathbf{3} \\ \mathbf{1} & \mathbf{2} & \mathbf{3} & \mathbf{4} & \mathbf{5} & \mathbf{6} & \mathbf{1} & \mathbf{2} & \mathbf{3} \\ \mathbf{1} & \mathbf{2} & \mathbf{3} & \mathbf{4} & \mathbf{5} & \mathbf{6} & \mathbf{1} & \mathbf{2} & \mathbf{3} \\ \mathbf{1} & \mathbf{2} & \mathbf{3} & \mathbf{4} & \mathbf{5} & \mathbf{6} & \mathbf{1} & \mathbf{2} & \mathbf{3} \\ \mathbf{1} & \mathbf{2} & \mathbf{3} & \mathbf{4} & \mathbf{5} & \mathbf{6} & \mathbf{1} & \mathbf{2} & \mathbf{3} \\ \mathbf{1} & \mathbf{2} & \mathbf{3} & \mathbf{4} & \mathbf{5} & \mathbf{6} & \mathbf{1} & \mathbf{2} & \mathbf{3} \\ \mathbf{1} & \mathbf{2} & \mathbf{3} & \mathbf{4} & \mathbf{5} & \mathbf{6} & \mathbf{1} & \mathbf{2} & \mathbf{3} \\ \mathbf{1} & \mathbf{2} & \mathbf{3} & \mathbf{4} & \mathbf{5} & \mathbf{6} & \mathbf{1} & \mathbf{2} & \mathbf{3} \\ \mathbf{1} & \mathbf{2} & \mathbf{3} & \mathbf{4} & \mathbf{5} & \mathbf{6} & \mathbf{1} & \mathbf{2} & \mathbf{3} \\ \mathbf{1} & \mathbf{2} & \mathbf{3} & \mathbf{4} & \mathbf{5} & \mathbf{6} & \mathbf{1} & \mathbf{2} & \mathbf{3} \\ \mathbf{1} & \mathbf{2} & \mathbf{3} & \mathbf{4} & \mathbf{5} & \mathbf{6} & \mathbf{1} & \mathbf{2} & \mathbf{3}\end{array}$

MY ADVISOR...

13....cares about me.

14 ....treats me fairly.

15 ....makes it okay to ask questions.

16 ....explains things that I don't understand.

17 ....shows me how to do things.

18 ....helps me solve problems by giving me information.

19....tellls me I did a good job when I've done something well.

20 ...nicely tells me when I made mistakes.

21 ....tells me how well I do on tasks.

22....makes sure I have what I need for school.

23....takes time to help me learn to do something well.

24 ... spends time with me when I need help.

$\begin{array}{lllllllll}1 & 2 & 3 & 4 & 5 & 6 & 1 & 2 & 3\end{array}$

$\begin{array}{lllllllll}1 & 2 & 3 & 4 & 5 & 6 & 1 & 2 & 3\end{array}$

$\begin{array}{lllllllll}1 & 2 & 3 & 4 & 5 & 6 & 1 & 2 & 3\end{array}$

$\begin{array}{lllllllll}1 & 2 & 3 & 4 & 5 & 6 & 1 & 2 & 3\end{array}$

$\begin{array}{lllllllll}1 & 2 & 3 & 4 & 5 & 6 & 1 & 2 & 3\end{array}$

$\begin{array}{lllllllll}1 & 2 & 3 & 4 & 5 & 6 & 1 & 2 & 3\end{array}$

$\begin{array}{lllllllll}1 & 2 & 3 & 4 & 5 & 6 & 1 & 2 & 3\end{array}$

$\begin{array}{lllllllll}1 & 2 & 3 & 4 & 5 & 6 & 1 & 2 & 3\end{array}$

$\begin{array}{lllllllll}1 & 2 & 3 & 4 & 5 & 6 & 1 & 2 & 3\end{array}$

$\begin{array}{lllllllll}1 & 2 & 3 & 4 & 5 & 6 & 1 & 2 & 3\end{array}$

$\begin{array}{lllllllll}1 & 2 & 3 & 4 & 5 & 6 & 1 & 2 & 3\end{array}$

$\begin{array}{lllllllll}1 & 2 & 3 & 4 & 5 & 6 & 1 & 2 & 3\end{array}$

\section{MY CLASSMATES...}

25 ... treat me nicely.

26. ..like most of my ideas and opinions.

27... pay attention to me. 


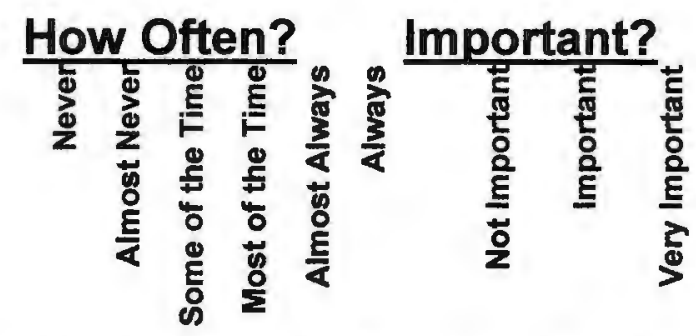

28... give me ideas when I don't know what to do.

$29 . .$. give me information so I can learn new things.

30 ....give me good advice.

31...tell me I did a good job when I've done something

$\begin{array}{lllllllll}1 & 2 & 3 & 4 & 5 & 6 & 1 & 2 & 3\end{array}$

$\begin{array}{llllllllll}1 & 2 & 3 & 4 & 5 & 6 & 1 & 2 & 3\end{array}$

$\begin{array}{lllllllll}1 & 2 & 3 & 4 & 5 & 6 & 1 & 2 & 3\end{array}$ well.

32... .nicely tell me when I make mistakes.

33... notice when I have worked hard.

34 ... ask me to join activities.

35....spend time doing things with me.

$36 . .$. help me with projects in class.

$\begin{array}{lllllllll}1 & 2 & 3 & 4 & 5 & 6 & 1 & 2 & 3 \\ 1 & 2 & 3 & 4 & 5 & 6 & 1 & 2 & 3 \\ 1 & 2 & 3 & 4 & 5 & 6 & 1 & 2 & 3 \\ 1 & 2 & 3 & 4 & 5 & 6 & 1 & 2 & 3 \\ 1 & 2 & 3 & 4 & 5 & 6 & 1 & 2 & 3\end{array}$

\section{MY CLOSE FRIEND...}

37....understands my feelings.

38 ....sticks up for me if others are treating me badly.

$39 . .$. helps me when I'm lonely.

$\begin{array}{lllllllll}1 & 2 & 3 & 4 & 5 & 6 & 1 & 2 & 3 \\ 1 & 2 & 3 & 4 & 5 & 6 & 1 & 2 & 3 \\ 1 & 2 & 3 & 4 & 5 & 6 & 1 & 2 & 3 \\ 1 & 2 & 3 & 4 & 5 & 6 & 1 & 2 & 3 \\ 1 & 2 & 3 & 4 & 5 & 6 & 1 & 2 & 3 \\ 1 & 2 & 3 & 4 & 5 & 6 & 1 & 2 & 3 \\ 1 & 2 & 3 & 4 & 5 & 6 & 1 & 2 & 3 \\ 1 & 2 & 3 & 4 & 5 & 6 & 1 & 2 & 3 \\ 1 & 2 & 3 & 4 & 5 & 6 & 1 & 2 & 3 \\ 1 & 2 & 3 & 4 & 5 & 6 & 1 & 2 & 3 \\ 1 & 2 & 3 & 4 & 5 & 6 & 1 & 2 & 3 \\ 1 & 2 & 3 & 4 & 5 & 6 & 1 & 2 & 3\end{array}$

\section{PEOPLE IN MY SCHOOL...}

49...care about me.

50 ....understand me.

51 ... listen to me when I need to talk.

$52 . .$. give me good advice.

53... help me solve my problems by giving me information.

54 ... explain things that I don't understand.

55 ....tell me how well $I$ do on tasks.

56...tell me I did a good job when I've done something well.

57 ....nicely tell me when I make mistakes.

58 ... take time to help me decide things.

$59 . .$. spend time with me when I need help. $\begin{array}{lllllllll}1 & 2 & 3 & 4 & 5 & 6 & 1 & 2 & 3 \\ 1 & 2 & 3 & 4 & 5 & 6 & 1 & 2 & 3 \\ 1 & 2 & 3 & 4 & 5 & 6 & 1 & 2 & 3 \\ 1 & 2 & 3 & 4 & 5 & 6 & 1 & 2 & 3 \\ 1 & 2 & 3 & 4 & 5 & 6 & 1 & 2 & 3\end{array}$

$\begin{array}{lllllllll}1 & 2 & 3 & 4 & 5 & 6 & 1 & 2 & 3\end{array}$

$\begin{array}{lllllllll}1 & 2 & 3 & 4 & 5 & 6 & 1 & 2 & 3\end{array}$

$\begin{array}{lllllllll}1 & 2 & 3 & 4 & 5 & 6 & 1 & 2 & 3\end{array}$

$\begin{array}{lllllllll}1 & 2 & 3 & 4 & 5 & 6 & 1 & 2 & 3 \\ 1 & 2 & 3 & 4 & 5 & 6 & 1 & 2 & 3 \\ 1 & 2 & 3 & 4 & 5 & 6 & 1 & 2 & 3\end{array}$




\section{Bibliography}

Bartone, P. T. (1999). Hardiness protects against war-related stress in army reserve forces. Consulting Psychology Journal, 51, 72-82.

Bernard, L. C., Hutchinson, S., Lavin, A., \& Pennington, P. (1996). Ego-strength, hardiness, self-esteem, self-efficacy, optimism, and maladjustment: Health-related personality constructs and the "Big Five" model of personality assessment. Psychological Assessment Resources, Inc., 3(2), 115-131.

Betz, N. E., Wohlgemuth, E., Serling, D., Harshbarger, J., \& Klein, K. (2001). Evaluation of a measure of self-esteem based on the concept of unconditional self-regard. Journal of Counseling \& Development, 74, 76-83.

Bitonti, C. (1992). The self-esteem of women: A cognitive-phenomenlogical study. Smith College Studies in Social Work, 63, 295-311.

Blascovich, J., \& Tomaka, J. (1991). Measures of self-esteem. In J. P. Robinson, P. R. Shaver \& J. S. Wrightsman (Eds.), Measures of personality and social psychological attitudes (pp. 115-160). San Diego, CA: Academic Press.

Blum, R. W., Beuhring, T., Shew, M. L., Bearinger, L. H., Sieving, R. E., \& Resnick, M. D. (2000). The effects of race/ethnicity, income, and family structure on adolescent risk behaviors. American Journal of Public Health, 90(12), 1-9.

Blum, R. W., McNeely, C. A., \& Rinehart, P. M. (2002). Improving the odds: The untapped power of schools to improve the health of teens. Minneapolis, MN: Center for Adolescent Health, University of Minnesota.

Bogenschneider, K., Wu, M., Rafaelli, M., \& Tsay, J. (1998). Other teens drink, but not my kid: Does parental awareness of adolescent alcohol use influence parents' 
responsiveness and adolescents' risky behaviors? Journal of Marriage and the Family, 60, 356-373.

Bonanno, G. A. (2004). Loss, trauma, and human resilience: Have we underestimated the human capacity to thrive after extremely aversive events? American Psychologist, $59(1), 20-28$.

Brand, S., Felner, R., Shim, M., Seitsinger, A., \& Dumas, T. (2003). Middle school improvement and reform: Development and validation of a school-level assessment of climate, cultural pluralism, and school safety. Journal of Educational Psychology, 95(3), 570-588.

Burgess, V., Dziegielewski, S., \& Green, C. (2005). Improving comfort about sex communication between parents and their adolescents: Practice-based research within a teen sexuality group. Brief Treatment \& Crisis Intervention, 5(4), 379390.

Butke, M. (2006). Cultivating hardiness: Group therapy research with urban adolescent girls. Unpublished doctoral dissertation, Smith College, North Hampton.

Caldwell, R., Pearson, J., \& Chin, R. (1987). Stress moderating effects: Social support in the context of gender and locus of control. Personality and Social Psychology Bulletin, 13, 5-17.

Cheng, H., \& Furnham, A. (2003). Personality, self-esteem and demographic predictions of happiness and depression. Personality and Individual Differences, 34(6), 921943.

Cicchetti, D., \& Toth, S. (1998). The development of depression in children and adolescents. American Psychologist, 53, 221-241. 
Cole, M., \& Cole, S. (2001). The Development of Children (4th ed.). New York: Worth Publishers.

Cooper, M. L., Wood, P. K., Orcutt, H. K., \& Albino, A. (2003). Personality and the predisposition to engage in risky or problem behaviors during adolescence. Journal of Personality \& Social Psychology, 84(2), 390-410.

Coopersmith, S. (1967). The Antecedents of self-esteem. San Francisco: W.H. Freeman and Company.

Demaray, M. K., \& Malecki, C. K. (2002). The relationship between perceived social support and maladjustment for students at risk. Psychology in the Schools, 39(3), 305-316.

Dwairy, M. (2004). Parenting styles and mental health of Arab gifted adolescents. Gifted Child Quarterly, 48(4), 275-287.

Felner, R. D. (2004). High performance learning community assessment report. Rock Island, IL: National Center on Public Education and Prevention.

Garmezy, N. (1991). Resilience and vulnerability to adverse developmental outcomes associate with poverty. American Behavioral Scientist, 34, 416-430.

Glodich, A. (1999). Psychoeducational groups for adolescents exposed to violence and abuse: Assessing the effectiveness of increasing knowledge of trauma to avert reenactment and risk-taking behavior. Unpublished Doctoral Dissertation, Smith College, Northhampton.

Gough, H. (1969). California psychological inventory manual. Palo Alto: Consulting Psychologists Press. 
Hannah, T., \& Morrissey, C. (1991). Correlates of psychological hardiness in Canadian adolescents. The Journal of Social Psychology, 1271(4), 339-344.

Harris, S. M. (2004). The effect of health value and ethnicity on the relationship between hardiness and health behaviors. Journal of Personality, 72(2), 379-411.

Harrison, T. W. (2003). Adolescent homosexuality and concerns regarding disclosure. Journal of School Health, 73(3), 107-113.

Harter, S. (1983). Developmental perspectives on the self-system. In E. M. Hetherington (Ed.), Handbook of child psychology: Socialization, personality, and social development (Vol. IV, pp. 276-368). New York: John Wiley \& Sons.

Harter, S. (1993). Causes and consequences of low self-esteem in children and adolescents. In R. Baumeister (Ed.), Self-esteem: The puzzle of low self regard. New York: Plenum Press.

Information works! 2005 measuring Rhode Island schools for change: State report card. (2005). Providence, RI: Rhode Island Department of Education and National Center on Public Education and Social Policy at the University of Rhode Island. Jones, M. C. (1957). The later careers of boys who were early- or late-maturing. Child Development, 28, 113-128.

Jordan, J. D. (2004). Hunger. Providence Journal, pp. A1, A8.

Keane, A., Ducette, J., \& Adler, D. (1985). Stress in ICU and non-ICU nurses. Nursing Research, 34, 231-236.

Keppel, G. (1991). Design and analysis: A researcher's handbook (Third ed.). Upper Saddle River, NJ: Prentice Hall, Inc. 
Khanlou, N. (2004). Influences on adolescent self-esteem in multicultural Canadian secondary schools. Public Health Nursing, 21(5), 404-412.

Khoshaba, D. M., \& Maddi, S. R. (2001). HardiTraining. Newport Beach, CA: Hardiness Institute.

Kobasa, S. C. (1979a). Personality and resistance to illness. American Journal of Psychology, 7(4), 413-423.

Kobasa, S. C. (1979b). Stressful life events, personality, and health: An inquiry into hardiness. Journal of Personality and Social Psychology, 37, 1-11.

Kobasa, S. C., Maddi, S. R., \& Kahn, S. (1982). Hardiness and health: A prospective study. Journal of Personality and Social Psychology, 42, 168-177.

Luthar, S. (1991). Vulnerability and resilience: A study of high-risk adolescents. Child Development, 62, 600-616.

Luthar, S., Cicchetti, D., \& Becker, B. (2000). The construct of resilience: A critical evaluation and guidelines for future work. Child Development, 71(3), 543-562.

Maddi, S. R. (1999). The personality construct of hardiness: I. Effects on experiencing, coping, and strain. Consulting Psychology Journal, 51(2), 83-94.

Maddi, S. R. (2002). The story of hardiness: Twenty years of theorizing, research and practice. Consulting Psychology Journal: Research and Practice, 54, 175-185.

Maddi, S. R. (2005). On hardiness and other pathways to resilience. American Psychologist, 60(3), 261-272.

Maddi, S. R., Harvey, R., Khoshaba, D. M., Lu, J., Persico, M., \& Brow, M. (2005). The personality construct of hardiness III: Relationships with repression, 
innovativeness, authoritarianism and performance.Unpublished manuscript, Irvine, CA.

Maddi, S. R., Kahn, S., \& Maddi, K. L. (1998). The effectiveness of hardiness training. Consulting Psychology Journal: Practice and Research, 50(2), 78-86.

Maddi, S. R., Khoshaba, D. M., Jensen, K., E/, C., Lu, J., \& Harvey, R. (2002). Hardiness training for high risk undergraduates. NACADA Journal, 22, 45-55.

Maddi, S. R., \& Kobasa, S. C. (1984). The hardy executive: Health under stress. Homewood, IL: Dow Jones-Irwin.

Mahoney, J. L., \& Stattin, H. (2000). Leisure activities and adolescent social behavior: The role of structure and social context. Journal of Adolescence, 23, 113-127.

Malecki, C. K., \& Demaray, M. K. (2002). Measuring perceived social support: Development of the child and adolescent social support scale (CASSS). Psychology in the Schools, 39(1), 1-18.

Malecki, C. K., Demaray, M. K., \& Elliott, S. N. (2000). A Working Manual on the Development of the Child and Adolescent Social Support Scale (CASSS): North Illinois University.

Manaster, G. J. (1989). Adolescent development. Itasca, Illinois: F.E. Peacock Publishers, Inc.

Marcia, J. E. (1980). Identity in adolescence. In J. Andelson (Ed.), Handbook of adolescent psychology. New York: John Wiley.

Masten, A. (2001). Ordinary magic. American Psychologist, 56(3), 227-238. 
Masten, A., Best, K., \& Garmezy, N. (1990). Resilience and development: Contributions from the study of children who overcome adversity. Development and Psychopathology, 2, 425-444.

Masten, A., \& Coatsworth, J. D. (1998). The development of competence in favorable and unfavorable environments. American Psychologist, 53(2), 205-220.

Masten, A., \& Garmezy, N. (1985). Risk, vulnerability, and protective factors in developmental psychopathology. In B. L. A. Kazdin (Ed.), Advances in clinical child psychology (Vol. 8, pp. 1-52). New York: Plenum Press.

McNamara, S. (2000). Stress in young people: What's new and what can we do? New York: Continuum.

Miller, P. H. (1993). Theories of developmental psychology (3rd ed.). New York: W.H. Freeman and Company.

Mussen, P. H., Jones, M.C. (1957). Self-conceptions, motivations and interpersonal attitudes of late- and early-maturing boys. Child Development, 28, 243-256.

Nowicki, S., \& Strickland, B. (1973). A locus of control scale for children. Journal of Consulting and Clinical Psychology, 40, 148-154.

Patterson, J., \& McCubbin, H. (1983). Adolescent-coping orientation for problem experiences (A-COPE). In Family assessment: Resiliency, coping, adaptation inventories for research and practice (pp. 537-583). Madison: University of Wisconsin System.

Perry, C. L. (2000). Preadolescent and adolescent influences on health. In B. D. Smedley \& S. L. Syme (Eds.), Promoting health: Intervention strategies from social and behavioral research (pp. 217-253). Washington, DC: National Academy Press. 
Pollock, K., \& Kymissis, P. (2001). The future of adolescent group therapy: An analysis of historical trends and current momentum. Journal of Child and Adolescent Group Therapy, 11(1), 3-11.

Porteous, M. A. (1981). Personal beliefs and the experience of problems: A study in adolescence. British Journal of Social Work, 11, 43-60.

Rhode Island Kids Count Factbook. (2000). Retrieved April 1, 2004, from http://www.rikidscount.org

Robins, R. W., Trzesniewski, K. H., Tracy, J. L., Gosling, S. D., \& Potter, J. (2002). Global self-esteem across the lifespan. Psychology and Aging, 17(3), 423-434. Rosenberg, M. (1967). Society and the adolescent self-image. Princeton, NJ: Princeton University Press.

Rutter, M. (1987). Psychosocial resilience and protective factors. American Journal of Orthopsychiatry, 57, 316-331.

Rutter, M. (1999). Resilience concepts and findings: Implications for family therapy. Journal of Family Therapy, 21, 119-144.

Sameroff, A. (1993). Models of development and developmental risk. In J. Charles H. Zeanah (Ed.), Handbook of infant mental health. New York: Guilford Press.

Sanford, J., \& McCabe, M. (2005). Evaluation of a body image prevention programme for adolescent boys. European Eating Disorders Review, 13, 360-370.

Santrock, J. W. (1999). Life-span development (7th ed.). Boston: McGraw-Hill College.

Sheppard, J. A., \& Kashani, J. H. (1991). The relationship of hardiness, gender, and stress to health outcomes in adolescents. Journal of Personality, 59(4), 747-768. 
Sheridan, S. M., \& Gutkin, T. B. (2000). The ecology of school psychology: Examining and changing our paradigm for the 21st century. School Psychology Review, 29(485-502).

Shirk, S., Burwell, R., \& Harter, S. (2003). Strategies to modify low self-esteem in adolescents. In M. Reinecke, F. Dattilio \& A. Freeman (Eds.), Cognitive therapy with children and adolescents (2nd ed., pp. 189-213). New York: Guilford Press.

Silber, E., \& Tippett, J. (1965). Self-esteem: Clinical assessment and measurement validation. Psychological Reports, 16, 1017-1071.

van Linden, J., \& Fertman, C. (1998). Youth leadership. San Francisco: Jossey-Bass, Inc. Wallace, K., Bisconti, T., \& Bergeman, C. (2001). The mediational effect of hardiness on social support and optimal outcomes in later life. Basic and Applied Social Psychology, 23(4), 267-279.

Werner, E. (1995). Resilience in development. Current Directions in Psychological Science, 4, 81-85.

Werner, E., \& Smith, R. (1977). Kauai's children come of age. Honolulu: University of Hawaii Press.

Werner, E., \& Smith, R. (1982). Vulnerable but invincible: A longitudinal study of resilient children and youth. New York: McGraw-Hill Book Company.

White, J. L. (1989). The troubled adolescent. New York: Pergamon Press.

Whiteside-Mansell, L., \& Corwyn, R. F. (2003). Mean and covariance structures analyses: An examination of the Rosenberg Self-Esteem Scale among adolescents. Educational \& Psychological Measurement, 63(1), 163-174. 
Wylie, R. C. (1974). The self-concept: A review of methodological considerations and measuring instruments (Vol. I). Lincoln, Nebraska: University of Nebraska Press.

Yarcheski, T. J., Mahon, N. E., \& Yarcheski, A. (2003). Social support, self-esteem, and positive health practices of early adolescents. Psychological Reports, 92(1), 99104. 